•研究报告・

\title{
澜沧江-泊公河中上游淡水鱼类多样性
}

\author{
李雪晴 1,2 孙赫英 1,2 何德奎 ${ }^{*}$ 陈毅峰 $^{1}$ \\ 1 (中国科学院水生生物研究所, 武汉 430072) \\ 2 (中国科学院大学, 北京 100049)
}

\begin{abstract}
摘要：澜沧江-湄公河是东南亚最大的河流，也是世界上淡水生物多样性最高的三大河流之一。由于特殊的地理位 置和国际河流属性, 澜沧江-涺公河淡水鱼类的多样性现状仍缺乏系统的认识。本文在近20年调查的基础上, 系统 整理了澜沧江-涺公河中上游32个支流或亚流域的淡水鱼类物种名录, 在此基础上对其种类组成和分布进行了分 析, 并利用分类学多样性指数对澜沧江-涺公河中上游流域的物种多样性进行了评估。结果表明, 澜沧江-涺公河 中上游共记录了淡水鱼类 745 种, 分属于 2 纲 17 目 63 科 229 属, 其中鲤形目鱼类 451 种, 占物种数的 $60.5 \%$ 。分类学多 样性指数显示, 从源头到中游, 淡水鱼类在分类阶元上的分布越来越均匀, 亲缘关系越来越远, 分类多样性越来 越高。聚类分析(cluster analysis, CA)和多维尺度分析(multi-dimensional scaling, MDS)表明, 当Jaccard相似性系数为 8.69时, 澜沧江-涺公河中上游32个亚流域可以分为源区、上游和中游3组; 相似性分析(ANOSIM)结果显示, 各组 之间淡水鱼类组成差异显著 $(R=0.877, P=0.001)$ 。相似性百分比分析(similarity percentage analysis, SIMPER)结果 表明, 导致 3 组差异性的鱼类主要是鲤形目和鲇形目鱼类, 且随着地势阶梯的升高出现了科级、属级类群的替代。 近几十年来, 随着流域各国人口的增长和经济的快速发展, 澜沧江一涺公河鱼类多样性和渔业资源面临严重威胁, 未来需加强流域内国家间合作，在流域尺度上制定科学保护计划。
\end{abstract}

关键词：澜沧江-湄公河; 淡水鱼类; 种类组成; 分类学多样性

\section{Freshwater fish diversity in the upper and middle reaches of the Lancang-Mekong River}

\author{
Xueqing $\mathrm{Li}^{1,2}$, Heying Sun ${ }^{1,2}$, Dekui $\mathrm{He}^{1^{*}}$, Yifeng Chen $^{1}$ \\ 1 Institute of Hydrobiology, Chinese Academy of Sciences, Wuhan 430072 \\ 2 University of Chinese Academy of Sciences, Beijing 100049
}

\begin{abstract}
The Lancang-Mekong River is the longest river in Southeast Asia, and is one of the richest areas of freshwater biodiversity in the world. Because it is an international river through six countries and holds extremely high fish biodiversity, there is a lack of systematic understanding of freshwater fish diversity. Over the past two decades, this team systematically compiled a list of freshwater fish species in 32 sub-basins or tributaries in the upper and middle reaches of the Lancang-Mekong River. Now in this paper, the species composition and distribution of fish have been analyzed, and the species diversity of the upper and middle reaches of the Lancang-Mekong River has been evaluated using the taxonomic diversity index. The results showed that 745 species of freshwater fish were recorded in the middle and upper reaches of the Lancang-Mekong River. These fish belong to 229 genera, 63 families, 17 orders and 2 classes. Of these, 451 species of Cypriniformes fish accounted for $60.5 \%$ of the species. The taxonomic diversity index showed that, from the source to the middle reaches of the river, the taxonomic distribution of freshwater fish became increasingly more even, the relationships were increasingly further apart, and the fish diversity gradually increased. Cluster analysis (CA) and multi-dimensional scaling analysis (MDS) results showed that the 32 sub-basins could be divided into three groups (Jaccard similarity coefficient=8.69), and the analysis of similarity (ANOSIM) indicated that the composition of freshwater fish differed significantly between the groups $(R=0.877, P=0.001)$. Similarity percentage analysis (SIMPER) results indicated that Cypriniformes
\end{abstract}

收稿日期: 2019-06-13; 接受日期: 2019-08-30

基金项目: 中国科学院东南亚生物多样性中心区域性国际合作基金(Y4ZK111B01)和中国科学院先导 A 类先导专项(XDA20050203)

* 通讯作者 Author for correspondence. E-mail: hedekui@ihb.ac.cn 
and Siluriformes were the main fish that differed among the three groups, and the species composition of groups presented distinctive changes at the family and species levels with the altitude rising. With the rapid population growth and economic development of the countries in the river basin in recent decades, the fish diversity and fishery resources of the Lancang-Mekong River face serious threats. Thus, it is urgent that countries in the river basin cooperate and formulate a scientific protection plan at the basin scale.

Key words: Lancang-Mekong River; freshwater fish; species composition; taxonomic diversity

生物多样性是人类赖以生存的物质基础, 包括 遗传多样性、物种多样性和生态系统多样性等多个 层次(戈峰, 2008), 而物种多样性是生物多样性最直 接也是最核心的体现(魏辅文等, 2014)。因此, 准确 描述、度量和评估物种多样性是生态学和保护生物 学长期关注的问题, 并为此提出了在不同尺度上的 物种多样性指数及基于这些多样性指数的多元分 析方法(蒋志刚和纪力强, 1999)。

澜沧江-涺公河是全球淡水生物多样性最高的 三大河流之一, 估计至少有890种淡水鱼类(Rainboth et al, 2012), 仅次于亚马孙河(Baran, 2010)。近 百年来, 众多科学家和国际组织(如湄公河委员会 MRC、WWF)对澜沧江-湄公河鱼类进行了长期、 持续的研究和编目, 但是, 由于澜沧江-湄公河极 高的多样性、复杂多样的生态系统、不断的新种和 新记录种发现以及分类学修订和变动, 加之该河流 的国际河流属性, 使得目前对该流域鱼类多样性的 现状和分布缺乏一个完整的认知。

澜沧江-涺公河中上游是指从源头到老挝南端 与柬埔寨的边界河段, 该流域内所有河段穿梭于高 原、山地和丘陵中, 山区巨大的垂直落差、高度的 景观异质性和多样的栖息环境, 加之中游又处于亚 热带季风地区, 以及地处青藏高原区、东洋区的东 亚区和南亚区的过渡地带，导致中上游不同河段、 支流间鱼类多样性变化明显, 区系组成差异显著。 此外, 中上游还是澜沧江-湄公河水能资源最丰富 的河段, 蕴藏了整个流域 $70 \%$ 以上的水能资源(陈丽 晖和何大明, 2000), 而澜沧江-涺公河流域水电开 发引起的下游渔业资源衰退又是国际关注的重要 生态环境问题。

本文依据1999-2017年澜沧江-湄公河流域实 地调查数据, 结合相关文献、专著、调查报告以及 在线数据库, 以支流和亚流域为地理单元, 系统收 集和整理了澜沧江-涺公河中上游淡水鱼类物种和 地理分布, 并对该区域的淡水鱼类种类组成和分布
进行了分析, 然后利用分类学多样性指数对澜沧江湄公河中上游流域的物种多样性进一步评估验证, 以期为澜沧江一湄公河鱼类多样性的保护和鱼类资 源的利用及管理提供科学依据。

\section{材料和方法}

\section{1 流域概况}

澜沧江一涺公河发源于中国青海省玉树州杂多 县莫云乡唐古拉山北麓, 流经中国境内青海、西藏 和云南三省后, 经缅甸、老挝、泰国、柬埔寨和越 南五国, 最后于越南胡志明市注入南海。全长约 $4,909 \mathrm{~km}$, 流域总面积约 $811,000 \mathrm{~km}^{2}$, 年径流量 $4.75 \times 10^{11} \mathrm{~m}^{3}$, 是著名的国际性河流(何大明, 1995)。澜沧江-湄公河为自北向南纵向性河流, 地 跨纬度 $30^{\circ}$, 地势北高南低, 呈条带状, 源头至河口 海拔落差达到 5,060 m以上(孙周亮等, 2018)。源区 位于青藏高原, 平均海拔在 $4,000 \mathrm{~m}$ 以上, 除高大险 峻的雪峰外, 山势平缓; 自云南德钦至中国、老挝 边界是纵贯中国西南部的纵向岭谷区, 该段落差达 $1,780 \mathrm{~m}$, 平均海拔 $1,200 \mathrm{~m}$; 从中老边界到老挝南 端, 河流坡度渐缓, 河道渐宽, 一些支流注入干流, 平均海拔为 $385 \mathrm{~m}$; 老挝南端至干丹省, 该段水文 情势变化巨大, 山区急流转变为缓流, 洞里萨湖便 位于该段内; 从干丹延伸至入海口属于河口区, 是 一个巨大的三角洲 (游珍等, 2014; 孙周亮等, 2018)。本文所研究区域为澜沧江一湄公河中上游流 域, 即从源头到老挝与柬埔寨交界之间的河段。

\section{2 地理单元(亚流域)划分}

在澜沧江一湄公河流域天然河流系统的基础上, 结合地形地貌、行政区划以及鱼类分布数据可获得 性等因素, 将湄公河中上游流域划分为32个亚流域 (Kang et al, 2009a; Baran, 2010; Ziv et al, 2012): 扎 曲(ZQ), 包括紫曲、昂曲、子曲和麦曲; 色曲(SQ), 包括若曲; 阿东河(AD); 永春河(YC); 通甸河(TD); 沘江(BJ), 包括腊普河、瓦窑河; 黑惠江(HH); 洱海 
(EH); 罗闸河(LZ); 小黑河(XH), 包括大寨河、芒帕 河; 秒嘎河(MG); 威远江(WY); 黑河(HR), 包括南 岸河; 大中河(DZ); 补远江(BY); 流沙河(LS), 包 括南垒河、南览河、南阿河; 南腊河(NL); 中老边 界至老挝博胶 (Bokeo) 北塔区 (Paktha) 的干流段 (MK-1); 北塔区至琅勃拉邦(Louang Phabang)南乌 江口的干流段(MK-2); 南乌江(Nam Ou River, NO); 南康河(Nam Khan River, NK); 琅勃拉邦南乌江口 至万象(Vientiane)南俄河河口的干流段(MK-3); 南 俄河(Nam Ngum River, NN); 南涅河(Nam Nhiep River, NNP); 南卡丁河(Nam Cadinh River, NC); 颂 堪河(Songkhram River, SG); 锡河(Chi River, CHI); 蒙河(Mun River, MUN); 色邦非河(Se Bang Fai River, SBF); 色邦亨河(Se Bang Hieng River, SBH); 塞公河(Se Kong River, SK); 颂堪河口至老挝与柬 埔寨边界的干流段(MK-4) (图1)。流域的划分采用 ArcMap 10.2软件。

\section{3 数据来源}

依据1999-2017年澜沧江和涺公河流域实地调 查数据, 包括国内样点 7 个, 泰国和老挝样点 16 个, 样点分布见图1, 并参考相关文献、专著、调查报告 (附录 1) 以及在线数据库 (Fishbase, Global Biodiversity Information Facility, MFD Fish Database 等), 排除同物异名, 更新分类地位变动。本文涉及 的淡水鱼类是指终生生活在淡水(初级淡水鱼类)和 生命某些阶段必须在淡水中度过的种类(如溯河和 降河洄游鱼类), 不包括分布在河口、海洋和偶然进 入淡水水域的物种以及外来物种。所有物种有效性 和分类地位在Catalog of Fishes数据库中进行确认 (Eschmeyer \& Fricke, 2019)。物种分布数据按亚流 域的存在/缺失形式整理。

\section{4 数据分析}

\subsection{1 鱼类组成相似度分析}

以 32 个亚流域的存在/缺失数据作为原始数据, 在Jaccard相似性系数的基础上构建相似性矩阵, 在 此基础上利用聚类分析(cluster analysis, CA)和多维 尺度分析(multi-dimensional scaling, MDS)展示鱼类 组成格局。利用相似性分析(analysis of similarities, ANOSIM)对聚类结果进行差异检验, 并通过对聚 类划分的亚流域组进行相似性百分比分析 (similarity percentage analysis, SIMPER)来确定造成 鱼类组成差异的主要贡献种属。Jaccard相似

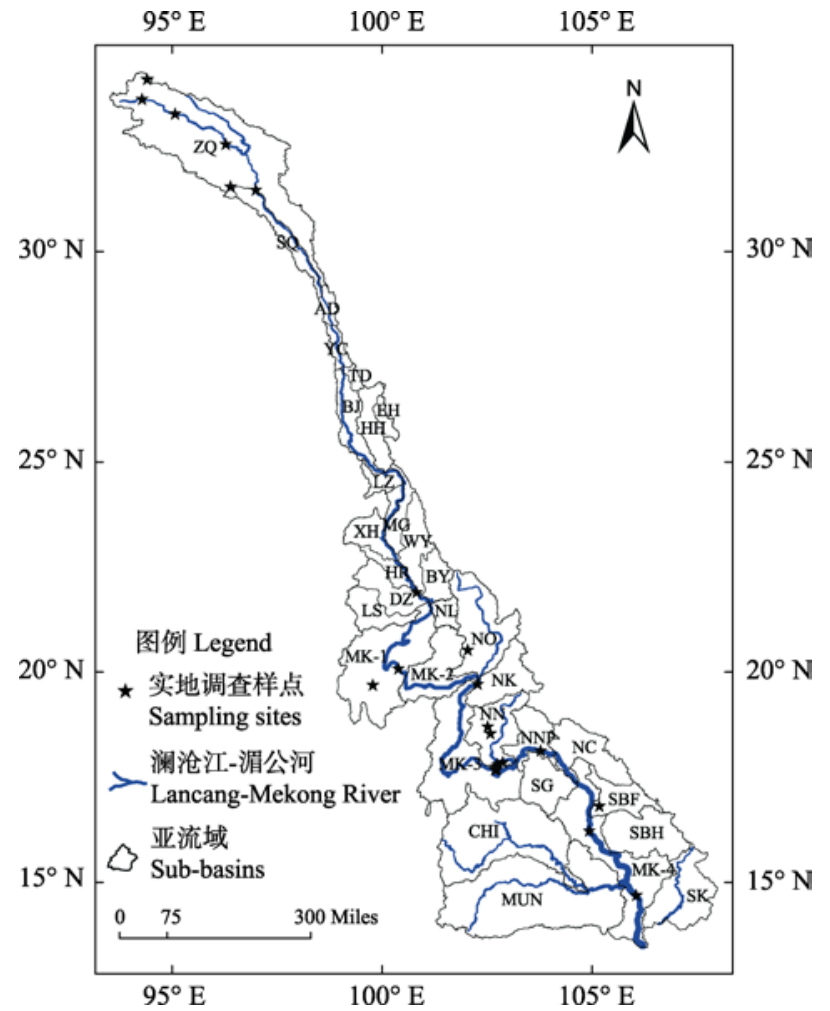

图1 澜沧江一湄公河中上游流域、地理单元(亚流域或支流) 以及调查样点分布图。亚流域划分: $Z Q$ : 扎曲; SQ: 色曲; AD: 阿东河; YC: 永春河; TD: 通甸河; EH: 洱海; BJ: 沘江; HH: 黑惠江; LZ: 罗闸河; MG: 虽嘎河; XH: 小黑河; WY: 威远江; HR: 黑河; BY: 补远江; LS: 流沙河; NL: 南腊河; DZ: 大中河; MK-1：中老边界一博胶; MK-2: 博胶一琅勃拉 邦南乌江口; NO: 南乌江; NK: 南康河; NN: 南俄河; MK-3: 琅勃拉邦南乌江口-万象南俄河口; NNP: 南涅河; NC: 南卡丁河; SG: 颂堪河; CHI: 锡河; MUN: 蒙河; SBF：色邦非河; SBH: 色邦亨河; SK: 塞公河; MK-4: 颂 堪河口-老挝与柬埔寨边界。

Fig. 1 Map of the upper and middle reaches of the Lancang-Mekong River, the geographic regions (sub-basins or tributaries) and investigation spots in this study. Sub-basins Division: ZQ: Zaqu; SQ: Sequ; AD: Adong River; YC: Yongchun River; TD: Tongdian River; EH: Erhai; BJ: Bijiang; HH: Heihui River; LZ: Luoza River; MG: Mengga River; XH: Xiaohei River; WY: Weiyuan River; HR: Hei River; BY: Buyuan River; LS: Liusha River; NL: Nanla River; DZ: Dazhong River; MK-1: The Border between China and LAOs-Bokeo, LAOs; MK-2: Bokeo-Nam Ou River Estuary, Luang Prabang; NO: Nam Ou River; NK: Nam Khan River; NN: Nam Ngum River; MK-3: Nam Ou River Estuary, Luang Prabang-Nam Ngum Estuary, Vientiane; NNP: Nam Nhiep River; NC: Nam Cadinh River; SG: Songkhram River; CHI: Chi River; MUN: Mun; SBF: Se Bang Fai River; SBH: Se Bang Hieng River; SK: Se Kong River; MK-4: Songkhram Estuary-the border between LAOs and Cambodia.

性系数计算公式:

$$
C_{j}=c /(a+b-c)
$$


式中, $a$ 为亚流域 $\mathrm{A}$ 的物种数, $b$ 为亚流域 $\mathrm{B}$ 的物种数, $c$ 为 $\mathrm{A} 、 \mathrm{~B}$ 两个亚流域之间的共有物种数。以上分析使 用PRIMER 6.0软件进行(Clarke \& Warwick, 2001b)。

\subsection{2 分类学多样性分析}

传统多样性指数受限于采样大小、方法, 忽略 了物种之间的差异和亲缘关系信息(Clarke \& Warwick, 1998, 2001a), 相同的计算结果可能对应 着完全不同的生态群落, 影响人们对群落结构的 理解和不同数据间的比较, 无法反映群落中生物分 类的变化(曲方圆和于子山, 2010)。因此, 我们采用 平均分类差异指数 (average taxonomic distinctness, $\Delta^{+}$) 和分类差异变异指数 (variation in taxonomic distinctness, $\left.\Lambda^{+}\right)$来评估澜沧江-湄公河中上游流域 淡水鱼类多样性:

$$
\begin{aligned}
& \Delta^{+}=\left(\Sigma \Sigma_{i<j} \omega_{i j}\right) /[S(S-1) / 2] \\
& \Lambda^{+}=\Sigma \Sigma_{i<j}\left(\omega_{i j}-\Delta^{+}\right)^{2} /[S(S-1) / 2]
\end{aligned}
$$

其中, $\omega_{i j}$ 为第 $i$ 和 $j$ 个种在分类系统树中的路径长度, $S$ 为物种数。

根据名录中不同分类等级水平的物种丰富度 设置不同分类等级间加权路径长的权重(徐宾铎等, 2005; Zhang et al, 2018), 将本研究的分类等级确定 为纲、目、科、属和种 5 个水平。采用PRIMER 6.0 软件包中的TAXDTEST进行数据分析(Warwick \& Clarke, 2001)。

\section{结果}

\section{1 物种组成}

澜沧江-湄公河中上游流域内共记录淡水鱼类 745种，隶属2纲17目63科229属(附录2)。

从目的种类组成来看, 鲤形目最多, 13科124属 451 种, 占总物种数的 $60.5 \%$; 其次是鲇形目, 12 科 37 属 144 种, 占物种数的 $19.3 \%$; 鲇形目排名第三, 16 科 29 属 67 种，占总物种数的 $9.0 \%$; 其余为合鳃 目、鲀形目、鲱形目、领针鱼目、鲽形目、骨舌鱼 目、海龙目、鲼形目、刺鱼目、鲳形目、鳗鳕目、 犁头鳐目、胡瓜鱼目、银汉鱼目 14 目, 共 22 科 39 属 83 种，占总物种数的 $11.2 \%$ 。

从科的组成来看: 以鲤科为主, 包含 190 种, 占 总数的 $25.5 \%$; 条鳅科次之, 107 种，占总数的 $14.4 \%$; 鿕科第三，53种，占总数的 $7.1 \%$; 鮡科 36 种, 占 总 数的 $4.8 \%$; 魭科 30 种, 占总数的 $4 \%$; 鲇科 28 种, 占
总数的 $3.8 \%$; 鳅科 26 种，占总数的 $3.5 \%$; 鱽科 20 种， 占总数的 $2.7 \%$; 爬鳅科和鲻科均为 18 种, 分别占总 数的 $2.4 \%$; 虾虎鱼科 17 种，占总数的 $2.3 \%$; 鲀科 15 种，占总数的 $2 \%$; 沙鳅科 14 种，占总数的 $1.9 \%$; 粒 鲇科 13 种，占总数的 $1.7 \%$ 。以上 15 科包括的物种数 超过湄公河中上游淡水鱼类物种总数的 $80 \%$ 。

从属的组成看, 物种数排列在前 10 位的分别是 南鳅属(Schistura)、波鱼属(Rasbora)、吻孔鲃属(Poropuntius)、纹胸鮡属(Glyptothorax)、鳠属(Mystus)、 神鿕属(Devario)、鲻属(Pangasius)、墨头鱼属 (Garra)、野鲮属(Labeo)、单孔鲀属(Pao)。

从分布频度看，宽额鳢(Channa gachua)频次最 多, 在 21 个亚流域中出现; 其次是大刺鳅(Mastacembelus armatus)和长嘴鱲(Raiamas guttatus), 在 20 个亚流域中出现; 最少的是泰国小眼刺鳅(Acantopsis thiemmedhi)、鞍斑粒鲇(Akysis ephippifer)、北 梭短吻鱼(Albulichthys albuloides)等240种鱼类，仅 出现在1个亚流域。

\section{2 分类学多样性指数}

根据物种名录计算得到澜沧江-泦公河中上游 淡水鱼类平均分类差异指数 $\left(\Delta^{+}\right)$和分类差异变异指 数 $\left(\Lambda^{+}\right)$(表 1)。平均分类差异指数 $\left(\Delta^{+}\right)$介于 56.92-72.31之间，在该范围内 $\Delta^{+}$值越大，表明亚流 域间的亲缘关系越远。从源头到中游, $\Delta^{+}$整体趋势 增大, 说明分类学等级水平越来越高, 亲缘关系也 越来越远，分类多样性越来越高。分类差异变异指 数 $\left(\Lambda^{+}\right)$介于182.76-550.32之间, 在该范围内 $\Lambda^{+}$值越 大，表明亚流域间的分类地位关系越不均匀。相对 来说, 阿东河的 $\Lambda^{+}$最大, 其次是扎曲、大中河、洱 海、永春、通甸河和色曲，说明源区附近的鱼类在分 类阶元上是最不均匀的, 颂堪河的 $\Lambda^{+}$最小, 其次是 锡河和颂堪河口至老挝与柬埔寨边界的干流段，说 明中游附近的鱼类在分类阶元上是最均匀的。

进一步做 $\Delta^{+}$和 $\Lambda^{+}$的95\%置信漏斗图(图2), 置信 漏斗中部的虚线是平均值曲线，其上方为最大值曲 线, 下方为最小值曲线。 $\Delta^{+}$的理论平均值为 69.5 , 源 区和上游亚流域的 $\Delta^{+}$值均低于平均值曲线，其中洱 海、扎曲、色曲、沘江、小黑河、补远江、流沙河、 南腊河、南乌江、塞公河低于最小值曲线，意味着 受到了扰动; 颂堪河、锡河、蒙河和颂堪河口至老 挝柬埔寨边界的干流段高于最大值曲线，说明流域 
表1 澜沧江-涺公河中上游32个亚流域平均分类差异指数 $\left(\Delta^{+}\right)$和分类差异变异指数 $\left(\Lambda^{+}\right)($河流代号见图1)。

Table 1 Average taxonomic distinctness $\left(\Delta^{+}\right)$and variation in taxonomic distinctness $\left(\Lambda^{+}\right)$of 32 sub-basins in the upper and middle Lancang-Mekong River. Sub-basin codes are shown in Fig. 1.

\begin{tabular}{|c|c|c|c|c|c|c|c|}
\hline $\begin{array}{l}\text { 亚流域 } \\
\text { Sub-basin }\end{array}$ & $\begin{array}{l}\text { 物种数 } \\
\text { Species number }\end{array}$ & $\begin{array}{l}\text { 平均分类差异指数 } \\
\text { Average taxonomic } \\
\text { distinctness }\left(\Delta^{+}\right)\end{array}$ & $\begin{array}{l}\text { 分类差异变异指数 } \\
\text { Variation in } \\
\text { taxonomic } \\
\text { distinctness }\left(\Lambda^{+}\right)\end{array}$ & $\begin{array}{l}\text { 亚流域 } \\
\text { Sub-basin }\end{array}$ & $\begin{array}{l}\text { 物种数 } \\
\text { Species number }\end{array}$ & $\begin{array}{l}\text { 平均分类差异指数 } \\
\text { Average taxonomic } \\
\text { distinctness }\left(\Delta^{+}\right)\end{array}$ & $\begin{array}{l}\text { 分类差异变异指数 } \\
\text { variation in } \\
\text { taxonomic } \\
\text { distinctness }\left(\Lambda^{+}\right)\end{array}$ \\
\hline ZQ & 17 & 60.88 & 434.52 & NL & 116 & 65.78 & 221.76 \\
\hline SQ & 24 & 61.45 & 348.62 & MK-1 & 240 & 68.52 & 233.13 \\
\hline $\mathrm{AD}$ & 10 & 60.89 & 550.32 & MK-2 & 99 & 67.47 & 232.44 \\
\hline YC & 21 & 63.05 & 379.28 & NO & 105 & 65.64 & 247.45 \\
\hline TD & 26 & 62.95 & 370.35 & NK & 85 & 67.68 & 227.93 \\
\hline BJ & 54 & 64.72 & 261.12 & MK-3 & 223 & 70.52 & 223.58 \\
\hline $\mathrm{HH}$ & 39 & 66.37 & 256.32 & NN & 157 & 67.92 & 224.96 \\
\hline $\mathrm{EH}$ & 23 & 56.92 & 396.82 & NNP & 123 & 69.65 & 220.26 \\
\hline LZ & 49 & 65.92 & 218.71 & NC & 104 & 69.47 & 226.98 \\
\hline $\mathrm{XH}$ & 62 & 65.67 & 221.7 & SG & 70 & 72.31 & 182.76 \\
\hline MG & 10 & 66.22 & 210.17 & CHI & 170 & 71.55 & 185.59 \\
\hline WY & 32 & 67.06 & 242.95 & MUN & 294 & 71.68 & 198.2 \\
\hline HR & 23 & 64.19 & 331.85 & SBF & 72 & 68.46 & 237.22 \\
\hline DZ & 11 & 60.73 & 406.74 & SBH & 157 & 69.83 & 216.84 \\
\hline BY & 100 & 66.5 & 247.27 & SK & 94 & 65.67 & 244.18 \\
\hline LS & 109 & 66.14 & 226.43 & MK-4 & 379 & 71.45 & 195.07 \\
\hline
\end{tabular}
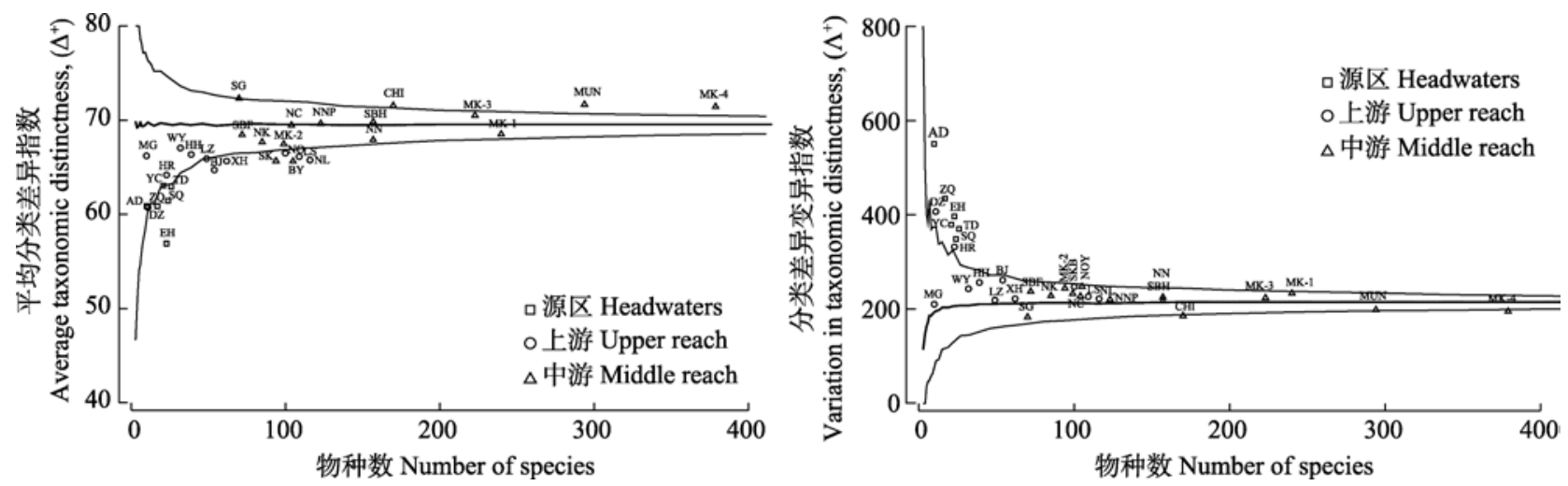

图2 澜沧江-湄公河中上游 32 个亚流域平均分类差异指数 $\left(\Delta^{+}\right)$和分类差异变异指数 $\left(\Lambda^{+}\right)$的 $95 \%$ 的置信区间漏斗图(河流代号 同图1)。

Fig. 2 The $95 \%$ probability funnels of average taxonomic distinctness $\left(\Delta^{+}\right)$and variation in taxonomic distinctness $\left(\Lambda^{+}\right)$for 32 sub-basins of the upper and middle reaches of Lancang-Mekong River. Sub-basin codes are shown in Fig. 1.

环境十分适宜, 物种的分类等级较多。 $\Lambda^{+}$的理论平 均值为 210 , 亚流域阿东河、扎曲、永春河、色曲、 大中河、黑河、通甸河和洱海高于最大值曲线, 说 明物种在分类等级间的分布均匀性较差。

\section{3 亚流域相似度}

根据Jaccard相似性系数对 32 个亚流域物种相 似性进行聚类分析结果表明, 当相似性系数为 8.69 时, 整个中上游流域可以分为 3 组(图3): 组 1 包括位
于涺公河源区的扎曲、色曲、阿东河、永春河和通 甸河; 组2包括位于湄公河上游的沘江、威远江、小 黑河、黑惠江、罗闸河、跁嘎河、大中河、黑河和 洱海; 组3包括位于涺公河中游的流沙河、南腊河、 补远江、中老边界至老挝博胶北塔区的干流段、北 塔区至琅勃拉邦南乌江口的干流段、琅勃拉邦南乌 江口至万象南俄河口的干流段、颂堪河至老挝与柬 埔寨边界的干流段、南乌江、南卡丁河、锡河、南 
康河、蒙河、南俄河、南涅河、色邦非河、色邦亨 河、塞公河、颂堪河。MDS排序图与聚类分析图一 致, 压力系数(Stress)为 0.09 , 而且补远江、南腊河和 流沙河三个亚流域鱼类组成重叠明显(图4)。

ANOSIM分析表明, 澜沧江-湄公河中上游流 域淡水鱼类组成的组间差异极为显著 $(R=0.877$,
$P=0.001)$, 各个分组间的差异均达到了极为显著 的水平 $\left(R_{\text {源区 } \& \text { 上游 }}=0.782, P=0.001 ; R_{\text {上游 } \& \text { 中游 }}=0.83\right.$, $P=0.001 ; R$ 源区 \&中游 $=1, P=0.001)$, 其中源区和中游 的鱼类组成差异是最大的。

相似性百分比分析(similarity percentage analysis，SIMPER)表明源区与上游、上游与中游、源区

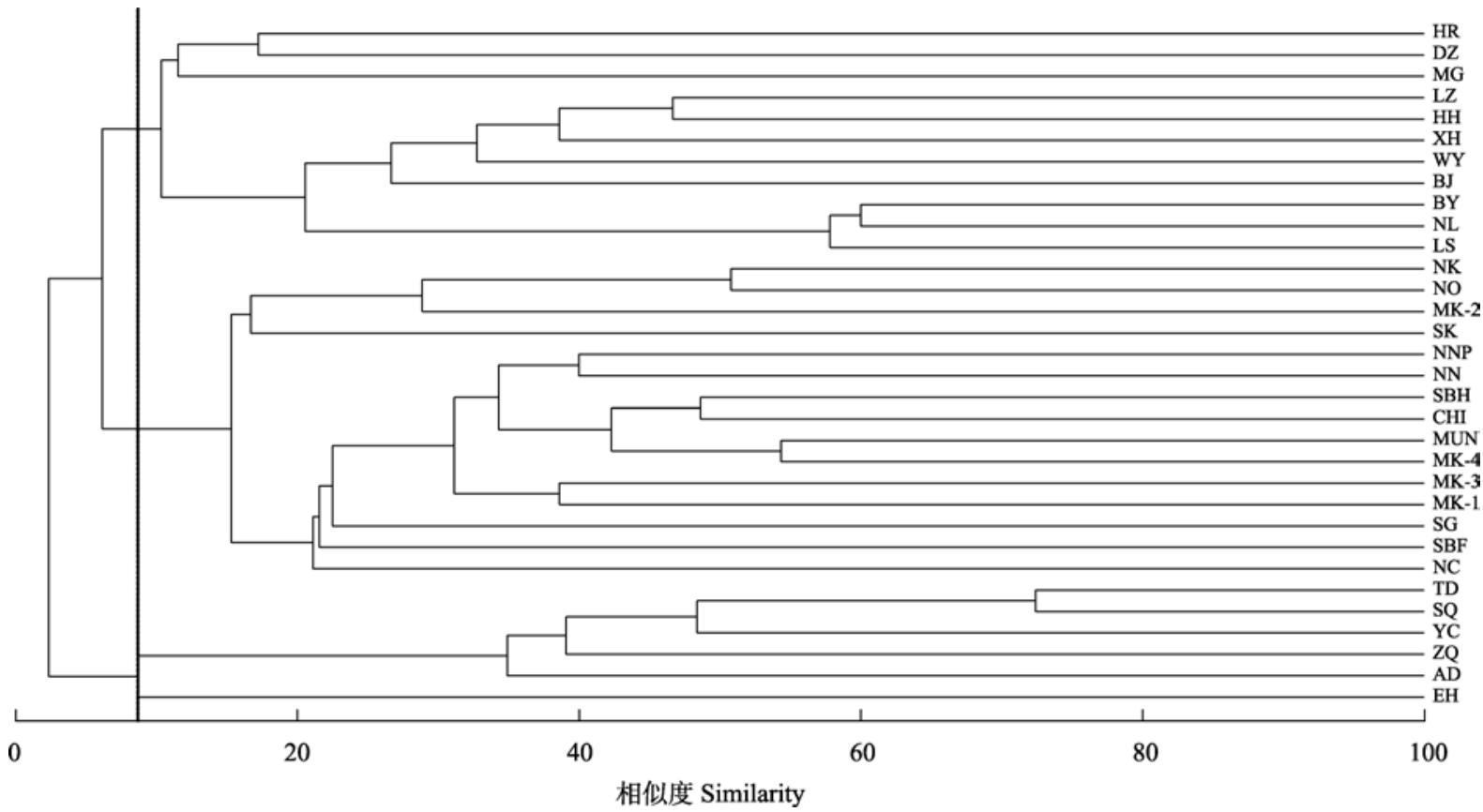

图3 基于Jaccard相似性矩阵和组平均聚类法构建的澜沧江-湄公河中上游32个亚流域淡水鱼类聚类树状图(河流代号见图1) Fig. 3 Cluster analysis of 32 sub-basins freshwater fish data for the upper and middle reaches of the Lancang-Mekong River based on Jaccard similarity matrix and group average clustering method. Sub-basin codes are shown in Fig. 1.

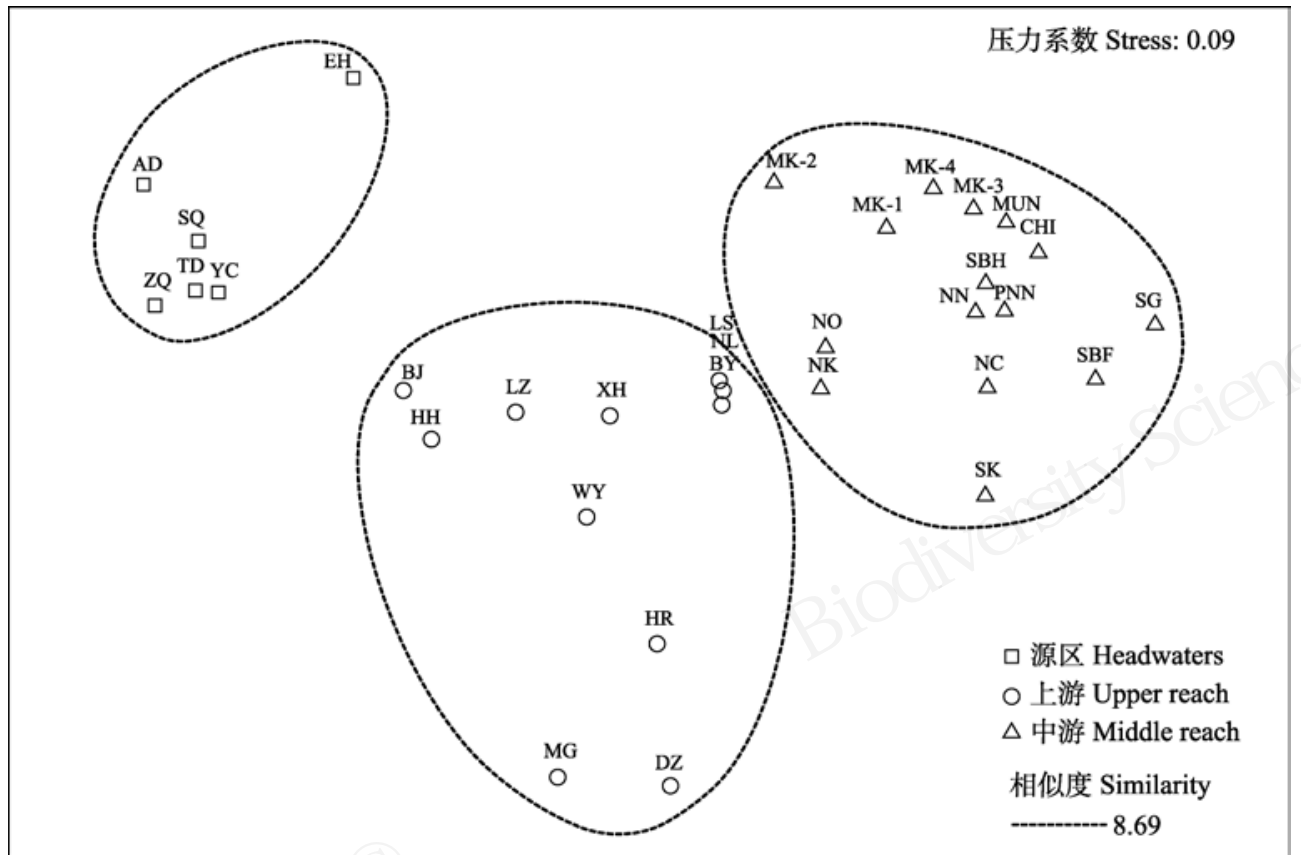

图4 基于Jaccard相似性 矩阵的澜沧江一涺公河中 上游32个亚流域淡水鱼类 组成的多维尺度分析 (MDS)排序图(河流代号见 图1)

Fig. 4 Multi-dimensional scaling analysis of freshwater fish in 32 sub-basins in the upper and middle reaches of the Lancang-Mekong River based on Jaccard similarity matrix. Subbasin codes are shown in Fig. 1. 
表2 澜沧江-湄公河中上游3个生物地理区淡水鱼类组成相似的主要属及其贡献率

Table 2 The genera contributing to similarity of freshwater fish composition among three biogeographical regions in the upper and middle reaches of the Lancang-Mekong River.

\begin{tabular}{|c|c|c|c|}
\hline $\begin{array}{l}\text { 关键属 } \\
\text { Key genus }\end{array}$ & $\begin{array}{l}\text { 源区和上游 } \\
\text { Headwaters \& upper reach }\end{array}$ & $\begin{array}{l}\text { 上游和中游 } \\
\text { Upper reach \& middle reach }\end{array}$ & $\begin{array}{l}\text { 源区和中游 } \\
\text { Headwaters \& middle reach }\end{array}$ \\
\hline 高鲮属 Altigena & 2.47 & - & - \\
\hline 纹胸鮡属 Glyptothorax & 7.62 & 2.37 & 2.15 \\
\hline 半鲿属 Hemibagrus & - & 1.9 & - \\
\hline 间吸鳅属 Hemimyzon & 2.4 & - & - \\
\hline 长慰鲃属 Mystacoleucus & - & 1.97 & 2.15 \\
\hline 鳠属 Mystus & - & 1.95 & 2.07 \\
\hline 纹唇鱼属 Osteochilus & - & 1.83 & 1.97 \\
\hline 无齿鲻属 Pangasianodon & - & 1.8 & - \\
\hline 单孔鲀属 Pao & - & 1.83 & 1.99 \\
\hline 鮡属 Pareuchiloglanis & 3.11 & - & - \\
\hline 吻孔鲃属 Poropuntius & 2.97 & 2.39 & 2.02 \\
\hline 褶鮡属 Pseudecheneis & 3.23 & - & - \\
\hline 波鱼属 Rasbora & - & 3.17 & 3.1 \\
\hline 南鲉属 Schistura & 2.83 & 3.92 & 2.79 \\
\hline 裂腹鱼属 Schizothorax & 6.25 & - & 2.61 \\
\hline 结鱼属 Tor & 2.68 & - & - \\
\hline 高原鱾属 Triplophysa & 6.18 & - & 2.27 \\
\hline
\end{tabular}

与中游间的鱼类组成平均差异百分比分别为 90.84\%、88.87\%和 $99.37 \%$ 。导致源区与上游的鱼类 组成差异的主要种属有: 纹胸鮡属、裂腹鱼属 (Schizothorax)、高原鳅属 (Triplophysa)、褶鮡属 (Pseudecheneis)、鮡属(Pareuchiloglanis)、吻孔鲃属、 南鳅属、结鱼属(Tor)、高鲮属(Altigena)和间吸鳅属 (Hemimyzon); 引起上游与中游鱼类组成差异的主 要种属有: 南鳅属、波鱼属、吻孔鲃属、纹胸鮡属、 长臀鲃属(Mystacoleucus)、鳠属、半鲿属(Hemibagrus)、纹唇鱼属(Osteochilus)、单孔鲀属和无齿鲳 属(Pangasianodon); 波鱼属、南鱾属、裂腹鱼属、 高原鳅属、纹胸鮡属、长慰鲃属、鳠属、吻孔鲃属、 单孔鲀属和纹唇鱼属是源区与中游鱼类组成差异 的主要属(表2)。

\section{3 讨论}

澜沧江一涺公河鱼类组成的最大特点之一是物 种多样性极高。由于独特的地理位置以及高度复杂 的栖息地环境, 澜沧江-湄公河鱼类物种的数量非
常惊人, 国外曾有研究估计涺公河鱼类物种有 1,200-1,300种(Rainboth, 1996; Dudgeon, 2011), 淡 水鱼类约有850种(Hortle, 2009; Dudgeon, 2011)。由 湄公河委员会开发的湄公河鱼类数据库(MFD)统计 有924种鱼类，其中土著鱼类898种(包括河口鱼类), 但这个数据库所覆盖流域不包括中国境内澜沧江 的物种数据信息(MRC, 2003)。关于澜沧江流域鱼类 的系统记载, 《云南鱼类志》中记录124种(褚新洛 和陈银瑞，1989，1990)，随后的研究表明澜沧江流 域记录了162种(Zhang et al, 2018), 与涺公河流域共 有的鱼类有61种(Kang et al, 2009a, b)。本研究首次 系统整理了澜沧江-湄公河中上游流域淡水鱼类物 种名录及其分布，澜沧江-湄公河记录有淡水鱼类 745种, 如果考虑下游分布物种, 整个澜沧江-湄公 河流域淡水鱼类接近 1,000 种, 物种数远超过我国 长江的淡水鱼类。一般认为, 物种多样性与河流的 自然环境、河流长度以及鱼类演化历史等因素密切 相关(MacArthur \& Wilson, 1967; 唐志尧等, 2009)。 澜沧江-涺公河作为一条自北向南纵向性河流, 地 
跨温带、亚热带和热带, 而长江为自西向东横向性 河流，下游河段地处亚热带。热带地区具有较高的 气温和充沛的降雨以及极高的初级生产力, 此外, 在地质历史时期也具有相对稳定的气候环境, 特别 是未受到第四纪冰期气候的影响。二者共同决定了 澜沧江一湄公河具有更高的鱼类多样性。

澜沧江-涺公河鱼类组成特点之二是鲇形目和 鲇形目所占比例有所增加。虽然仍以鲤形目为主, 占到物种总数的 $60.5 \%$, 但与我国其他大型河流相 比, 如长江(77.78\%)、黄河(75.15\%)和珠江(81.47\%) 等(未发表数据), 澜沧江一涺公河鲤形目所占比例有 所下降, 而鲇形目 (占总数的 19.3\%)和鲈形目 (占总 数的 $9 \%$ )所占比例则上升。这与澜沧江-泦公河鱼类 区系演化历史有关。澜沧江-涺公河地处东亚区与 南亚区鱼类区系的过渡地带，区系组成包括了来自 冈瓦纳古陆、新生代东亚起源以及东南亚起源鱼 类。而我国东部水系则更多是东亚起源鱼类为主。

澜沧江-湄公河鱼类组成特点之三是大型淡水 鱼类和洄游性鱼类丰富。全球最大的 10 种淡水鱼类 中有 4 种分布于湄公河, 包括巨赤鯐 (Himantura chaophraya)、巨无齿鲻(Pangasianodon gigas)、长丝 鲻(Pangasius sanitwongsei)和暹罗巨鲤(Catlocarpio siamensis), 其中暹罗巨鲤是现存鲤科鱼类中个体 最大的物种, 体重可达 $300 \mathrm{~kg}$, 体长达 $300 \mathrm{~cm}$ 。泗斿 鱼类有135种(Baran, 2006), 而且主要以大型鱼类为 主(Poulsen et al, 2002; Ziv et al, 2012)。

从聚类分析 $(\mathrm{CA})$ 结果来看, 在Jaccard相似性系 数为 8.69 时可以将 32 个亚流域分为源区、上游和中 游3组, ANOSIM检验结果也验证了 3 组彼此之间的 鱼类组成差异极其显著, 这种差异与澜沧江-涺公 河流域自然条件密切相关。根据SIMPER分析结果, 源区的种类以裂腹鱼属和高原鳅属等高原鱼类为 主, 这些类群适应高海拔、低水温、流水和贫营养 环境, 属于典型的青藏高原区鱼类区系; 而上游则 以纹胸鮡属和吻孔鲃属等过渡性鱼类为主, 即青藏 高原向云贵高原过渡的种类; 中游主要是长慰鲃属 和波鱼属等东洋区鱼类，该段流域河谷开阔、水流 减缓、海拔较低、水温较高。虽然鲤形目和鲇形目 鱼类在各个组中均占到很大比例, 但随着地势阶梯 的升高出现了科级、属级类群的替代, 适应暖水性 的类群如长臀鲃属、波鱼属、鳠属等逐渐减少, 取
而代之的是适应冷水和激流的裂腹鱼属、高原鲀属 和鮡科鱼类(表3)。

分类学多样性指数是基于物种的进化和亲缘 关系来评估生物多样性(Clarke \& Warwick, 1998), 并且不受采样大小、采样方法和生境类型等因素的 影响(Clarke \& Warwick, 1998, 2001b), 已经被广泛 研究证明在生物多样性研究方面较传统指数具有 一定优势(Jiang et al, 2019)。本研究中平均分类差异 指数 $\left(\Delta^{+}\right)$和分类差异变异指数 $\left(\Lambda^{+}\right)$的计算只考虑物 种的出现与否, 而不考虑种类的数量, 这实际上是 对群落中优势种与常见种权重的最简化处理(徐宾 铎等, 2005), 因此, 本研究中利用澜沧江-湄公河中 上游流域淡水鱼类数据进行分类多样性分析是可 行的和合理的。通常认为, 在同等物种组成的群落 中, 物种归属于多个属的群落的生物多样性高于物 种归属于一个属的群落。因此, 从源头到中游, 淡 水鱼类的生物多样性逐渐升高, 群落结构越来越稳 定。本研究中, 从源头到中游, 淡水鱼类在分类阶 元上的分布越来越均匀, 亲缘关系越来越远, 分类 多样性越来越高, 同样也体现了这一结果。

澜沧江-涺公河作为全球重要的国际河流和淡 水鱼类多样性最高的河流之一, 其生物多样性现状 和面临的威胁长期受到学界关注(Kang et al, 2009a; Valbo-Jørgensen et al, 2009; Baran, 2010; Kano et al, 2016; Zhang et al, 2018)。涺公河分布有世界上最大 的 10 种淡水鱼类中的 4 种, 也是全球最重要的鱼类 洄游栖息地之一，同时，该流域以自然捕捞为主的 淡水渔业是东南亚人民最重要的动物蛋白来源。然 而，近30年来，随着流域各国人口的增长和经济的 快速发展, 澜沧江-涺公河淡水生物多样性和渔业 资源面临严重威胁(Ziv et al, 2012)。特别是近年来 以水利工程建设和过度捕捞为主的人类活动, 使得 澜沧江-湄公河淡水生态系统正面临生境破碎化、 栖息地丧失、鱼类洄游通道阻隔、生物入侵等生态 环境问题(Dudgeon et al, 2006; Kang et al, 2009b; Zhang et al, 2018)。然而, 由于澜沧江-湄公河流域 特殊的地理位置和地缘特点以及极高的鱼类多样 性, 全面深入了解该流域鱼类多样性和分布, 探索 流域尺度上的多样性变动及其归因仍然是极大的 挑战。今后, 加强流域内国家间合作, 实现数据共 享, 在流域尺度上制定保护计划迫在眉睫。 
表3 河源、上游和中游鱼类组成相似性的主要属及其贡献率

Table 3 The genera contributing to similarity of fish composition within headwaters, upper and middle reaches

\begin{tabular}{|c|c|c|c|c|}
\hline & 目 Order & 科 Family & 属 Genus & 贡献率 Contribution (\%) \\
\hline \multirow[t]{10}{*}{ 源区 Headwaters } & \multirow[t]{6}{*}{ Cypriniformes } & \multirow[t]{3}{*}{ 鲤科 Cyprinidae } & 裂腹鱼属 Schizothorax & 34.43 \\
\hline & & & 叶须鱼属 Ptychobarbus & 2.04 \\
\hline & & & 裸裂尻鱼属 Schizopygopsis & 2.04 \\
\hline & & \multirow[t]{2}{*}{ 条鳅科 Nemacheilidae } & 高原鱾属 Triplophysa & 16.11 \\
\hline & & & 荷马条鱾属 Homatula & 2.13 \\
\hline & & 爬鳅科 Balitoridae & 拟平鳅属 Pseudohomaloptera & 2.13 \\
\hline & \multirow[t]{4}{*}{ Siluriformes } & \multirow[t]{4}{*}{ 鮡科 Sisoridae } & 纹胸鮡属 Glyptothorax & 9.86 \\
\hline & & & 鮡属 Pareuchiloglanis & 7.95 \\
\hline & & & 褶鮡属 Pseudecheneis & 6.74 \\
\hline & & & 异鮡属 Creteuchiloglanis & 4.61 \\
\hline \multirow{10}{*}{$\begin{array}{l}\text { 上游 } \\
\text { Upper reach }\end{array}$} & \multirow[t]{7}{*}{ Cypriniformes } & \multirow[t]{6}{*}{ 鲤科 Cyprinidae } & 吻孔鲃属 Poropuntius & 7.07 \\
\hline & & & 舟齿鱼属 Scaphiodonichthys & 4.7 \\
\hline & & & 结鱼属 Torg & 4.13 \\
\hline & & & 高鲮属 Altigena & 3.42 \\
\hline & & & 墨头鱼属 Garra & 3.4 \\
\hline & & & 东坡墨鱼属 Ageneiogarra & 3.01 \\
\hline & & 条鲉科 Nemacheilidae & 南䱊属 Schistura & 3.91 \\
\hline & \multirow[t]{3}{*}{ Siluriformes } & \multirow[t]{2}{*}{ 鮡科 Sisoridae } & 纹胸鮡属 Glyptothorax & 8.86 \\
\hline & & & 褶鮡属 Pseudecheneis & 4.1 \\
\hline & & 锡伯鲶科 Ailiidae & 鲱鲶属 Clupisoma & 2.98 \\
\hline \multirow{10}{*}{$\begin{array}{l}\text { 中游 } \\
\text { Middle reach }\end{array}$} & \multirow[t]{6}{*}{ Cypriniformes } & \multirow[t]{4}{*}{ 鲤科 Cyprinidae } & 长慰鲃属 Mystacoleucus & 4 \\
\hline & & & 圆唇鱼属 Cyclocheilichthys & 2.66 \\
\hline & & & 裂峡鲃属 Hampala & 2.48 \\
\hline & & & 纹唇鱼属 Osteochilus & 2.7 \\
\hline & & \multirow[t]{2}{*}{ 鲆科 Danionidae } & 波鱼属 Rasbora & 3.91 \\
\hline & & & 真马口波鱼属 Opsarius & 3.74 \\
\hline & 鲈形目 Perciformes & 鳢科 Channidae & 鳢属 Channa & 3.36 \\
\hline & 合鳃目 Synbranchiformes & 刺鳅科 Mastacembelidae & 刺鳅属 Mastacembelus & 2.3 \\
\hline & 鲇形目 Siluriformes & 魭科 Bagridae & 鳠属 Mystus & 2.28 \\
\hline & 鲀形目 Tetraodontiformes & 鲀科 Tetraodontidae & 单孔鲀属 $P a o$ & 2.22 \\
\hline
\end{tabular}

致谢: 周卓诚博士、隋晓云博士、豪富华博士、刘 光博士和张梦淇博士协助老挝调查, 特此感谢!

\section{参考文献}

Baran E (2006) Fish Migration Triggers in the Lower Mekong Basin and Other Tropical Freshwater Systems. MRC Technical Paper No. 14, Mekong River Commission, Vientiane.

Baran E (2010) Mekong fisheries and mainstream dams. In: ICEM 2010, pp. 1-145. Mekong River Commission Strategic Environmental Assessment of Hydropower on the Mekong Mainstream, International Centre for Environmental Management, Hanoi, Vietnam.
Chen LH, He DM (2000) The ecological impacts of hydropower cascade development in Lancang-Mekong River. Acta Geographica Sinica, 67, 577-586. (in Chinese with English abstract) [陈丽晖, 何大明 (2000) 澜沧江-湄公河水电梯 级开发的生态影响. 地理学报, 67, 577-586.]

Chu XL, Chen YR (1989) The Fishes of Yunnan, China Part I. Science Press, Beijing. (in Chinese) [禇新洛, 陈银瑞(1989) 云南鱼类志(上册). 科学出版社, 北京.]

Chu XL, Chen YR (1990) The Fishes of Yunnan, China Part II. Science Press, Beijing. (in Chinese) [褚新洛, 陈银瑞 (1990) 云南鱼类志(下册). 科学出版社, 北京.]

Clarke KR, Warwick RM (1998) A taxonomic distinctness index and its statistical properties. Journal of Applied 
Ecology, 35, 523-531.

Clarke KR, Warwick RM (2001a) A further biodiversity index applicable to species lists: Variation in taxonomic distinctness. Marine Ecology Progress Series, 216, 265-278.

Clarke KR, Warwick RM (2001b) Change in marine communities: An approach to statistical analysis and interpretation, 2nd edn. Plymouth Marine Laboratory, Plymouth.

Dudgeon D (2011) Asian river fishes in the Anthropocene: Threats and conservation challenges in an era of rapid environmental change. Journal of Fish Biology, 79, 1487-1524.

Dudgeon D, Arthington AH, Gessner MO, Kawabata Z, Knowler DJ, Leveque C, Naiman RJ, Prieur RAH, Soto D, Stiassny MLJ, Sullivan CA (2006) Freshwater biodiversity: Importance, threats, status and conservation challenges. Biological Reviews, 81, 163-182.

Eschmeyer WN, Fricke R (2019) Catalog of Fishes: Genera, Species, References. http://researcharchive.calacademy.org/ research/ichthyology/catalog/fishcatmain.asp. (accessed on 2019-02-28)

Ge F (2008) Modern Ecology, 2nd edn. Science Press, Beijing. (in Chinese) [戈峰 (2008) 现代生态学, 第2版. 科学出版 社, 北京.]

He DM (1995) Analysis of hydrological characteristics in Lancang-Mekong River. Yunnan Geographic Environment Research, 7, 58-74. (in Chinese with English abstract) [何大 明 (1995) 澜沧江-湄公河水文特征分析. 云南地理环境 研究, 7, 58-74.]

Hortle KG (2009) Chapter 9-Fisheries of the Mekong River Basin. In: The Mekong (ed. Campbell IC), pp.197-249. Academic Press, San Diego.

Jiang XM, Ding CZ, Brosse S, Pan B, Lu Y, Xie ZC (2019) Local rise of phylogenetic diversity due to invasions and extirpations leads to a regional phylogenetic homogenization of fish fauna from Chinese isolated plateau lakes. Ecological Indicators, 101, 388-398.

Jiang ZG, Ji LQ (1999) Avian-mammalian species diversity in nine representative sites in China. Chinese Biodiversity, 7, 220-225. (in Chinese with English abstract) [蒋志刚, 纪力 强 (1999) 鸟兽物种多样性测度的 $G-F$ 指数方法. 生物多 样性, 7, 220-225.]

Kang B, He DM, Perrett L, Wang HY, Hu WX, Deng WD, Wu YF (2009a) Fish and fisheries in the upper Mekong: Current assessment of the fish community, threats and conservation. Reviews in Fish Biology and Fisheries, 19, 465-480.

Kang B, Perrett L, Li YG, He DM (2009b) Are the fish of the upper and lower Mekong interconnected. Chinese Journal of Oceanology and Limnology, 27, 400-407.

Kano Y, Dudgeon D, Nam S, Samejima H, Watanabe K, Grudpan C, Grudpan J, Magtoon W, Musikasinthorn P, Nguyen PT, Praxaysonbath B, Sato T, Shibukawa K, Shimatani Y, Suvarnaraksha A, Tanaka W, Thach P, Tran DD, Yamashita
T, Utsugi K (2016) Impacts of dams and global warming on fish biodiversity in the Indo-Burma hotspot. PLoS ONE, 11, e0160151.

MacArthur RH, Wilson EO (1967) The Theory of Island Biogeography. Princeton University Press, Princeton.

MRC (2003) Mekong Fish Database: A Taxonomic Fish Database for the Mekong Basin. Mekong River Commission, Phnom Penh.

Poulsen AF, Poeu O, Viravong S, Suntornratana U, Tung NT (2002) Fish migrations of the Lower Mekong River Basin: Implications for Development, Planning and Environmental Management. MRC Technical Paper No.8, Mekong River Commission, Phnom Penh.

Qu FY, Yu ZS (2010) The application of taxonomic diversity in macrobenthic ecology: Taking Yellow Sea for example. Biodiversity Science, 18, 150-155. (in Chinese with English abstract) [曲方圆, 于子山 (2010) 分类多样性在大型底 栖动物生态学方面的应用: 以黄海底栖动物为例. 生物 多样性, 18, 150-155.]

Rainboth WJ (1996) Fishes of the Cambodian Mekong. FAO Species Identification Field Guide for Fishery Purposes, FAO, Rome.

Rainboth WJ, Vidthayanon C, Mai DY (2012) Fishes of the Greater Mekong Ecosystem with Species List and Photographic Atlas. Miscellaneous Publications No. 201, University of Michigan, Museum of Zoology, Ann Arbor.

Sun ZL, Liu YL, Liu J, Zhao ZX, Wang GX, Jin JL, Bao ZX, Liu CS (2018) Analysis on the present situation and demand of water utilization in the Lancang-Mekong River Basin. Journal of Water Resources \& Water Engineering, 29(4), 70-76. (in Chinese with English abstract) [孙周亮, 刘艳丽, 刘冀, 赵志轩, 王高旭, 金君良, 鲍振金金, 刘翠善 (2018) 澜沧江-湄公河流域水资源利用现状与需求分析. 水资源 与水工程学报, 29(4), 70-76.]

Tang ZY, Wang ZH, Fang JY (2009) Historical hypothesis in explaining spatial patterns of species richness. Biodiversity Science, 17, 635-643. (in Chinese with English abstract) [唐 志尧, 王志恒, 方精云 (2009) 生物多样性分布格局的地 史成因假说. 生物多样性, 17, 635-643.]

Valbo-Jørgensen J, Coates D, Hortle KG (2009) Chapter 8-Fish diversity in the Mekong River basin. In: The Mekong (ed. Campbell IC), pp.161-196. Academic Press, San Diego.

Warwick RM, Clarke KR (2001) Practical measures of marine biodiversity based on relatedness of species. Oceanography and Marine Biology: An Annual Review, 39, 207-231.

Wei FW, Nie YG, Miao HX, Lu H, Hu YB (2014) Advancements of the researches on biodiversity loss mechanisms. Chinese Science Bulletin, 59, 430-437. (in Chinese with English abstract) [魏辅文, 聂永刚, 苗海霞, 路浩, 胡义波 (2014) 生物多样性丧失机制研究进展. 科学通报, 59, 
430-437.]

Xu BD, Jin XS, Liang ZL (2005) Calculation of hierarchical diversity of fish in the Huanghai and Bohai Seas. Periodical of Ocean University of China (Natural Science), 35, 25-28. (in Chinese with English abstract) [徐宾铎, 金显仕, 梁振 林 (2005) 对黄、渤海鱼类等级多样性的推算. 中国海洋 大学学报(自然科学版), 35, 25-28.]

You Z, Feng ZM, Jiang LG, Yang YZ (2014) Population distribution and its spatial relationship with terrain elements in Lancang-Mekong River Basin. Mountain Research, 32, 21-29. (in Chinese with English abstract) [游珍, 封志明, 姜鲁光, 杨艳昭 (2014) 澜沧江-湄公河流域人口分布及
其与地形的关系. 山地学报, 32, 21-29.]

Zhang C, Ding L, Ding C, Chen L, Sun J, Jiang X (2018) Responses of species and phylogenetic diversity of fish communities in the Lancang River to hydropower development and exotic invasions. Ecological Indicators, 90, 261-279.

Ziv G, Baran E, Nam S, Rodríguez-Iturbe I, Levin SA (2012) Trading-off fish biodiversity, food security, and hydropower in the Mekong River Basin. Proceedings of the National Academy of Sciences, USA, 109, 5609-5614.

(责任编委：陈小勇 责任编辑：时意专)

\section{附录 Supplementary Material}

\section{附录1 本文用于整理淡水鱼类名录的文献、专著和调查报告}

Appendix 1 Literatures, monographs and investigation reports for the compilation of freshwater fish list in this paper http://www.biodiversity-science.net/fileup/PDF/2019195-1.pdf

附录2 澜沧江-湄公河中上游32个亚流域淡水鱼类物种名录

Appendix 2 List of freshwater fish species in 32 sub-basins of the upper and middle reaches of Lancang-Mekong River http://www.biodiversity-science.net/fileup/PDF/2019195-2.pdf 
附录1 本文用于整理淡水鱼类名录的文献、专著和调查报告

Appendix 1 Literatures, monographs and investigation reports for the compilation of freshwater fish list in this paper

Chen XY (2013) Checklist of fishes of Yunnan. Zoological Research, 34, 281-343.(in Chinese with English abstract) [陈小勇 (2013) 云南鱼类名录. 动物学研究, 34, 281-343.]

Chu XL, Chen YR (1989) The Fishes of Yunnan, China Part I. Science Press, Beijing. (in Chinese) [禇新洛, 陈银瑞(1989) 云南鱼类志(上册). 科学出版社, 北 京.]

Chu XL, Chen YR (1990) The Fishes of Yunnan, China Part II. Science Press, Beijing. (in Chinese) [禇新洛, 陈银瑞 (1990) 云南鱼类志(下册). 科学出版社, 北 京.]

Doi A (1997) A review of taxonomic studies of Cypriniform fishes in southeast Asia. Japanese Journal of Ichthyology, 44(1), 1-33.

He YM, Yang TL, Liu J, Yang ZZ (2010) The investigation of the fish current resources in Erhai Lake. Journal of Chuxiong Normal University, 25(3), 53-58. (in Chinese with English abstract) [何彦敏, 杨堂亮, 刘杰, 杨自忠 (2010) 洱海鱼类资源现状调查研究. 楚雄师范学院学报, 25(3), 53-58.]

He SP, Wang W, Chen YR, Li ZY, Yang JX (1999) The preliminary investigation of fish biodiversity in middle and upper reach of Lancangjiang River. Yunnan Geographic Environment Research, 11, 26-29. (in Chinese with English abstract) [何舜平，王伟，陈银瑞，李再云，杨君兴 (1999) 澜沧江中上游鱼类生物多样 性现状初报. 云南地理环境研究, 11, 26-29.].

Kang B, He DM, Perrett L, Wang HY, Hu WX, Deng WD, Wu YF (2009) Fish and fisheries in the upper Mekong: Current assessment of the fish community, threats and conservation. Reviews in Fish Biology and Fisheries, 19, 465-480.

Kang B, He DM (2007) Research Progress of Biodiversity of Fish Species in the Lancangjiang River. Resources Science, 29(5), 195-200. (in Chinese with English abstract) [康斌, 何大明 (2007) 澜沧江鱼类生物多样性研究进展. 资源科学, 29(5), 195-200.]

Kang B, Hu WX, Qi WL, Yang CM, Li JH (2010) Research on fish species diversity in the Buyuan River. Progress in fishery sciences, 31(3), 6-14. (in Chinese with English abstract) [康斌，胡文涃，祁文龙，杨春明，李江红 (2010) 补远江鱼类多样性研究. 渔业科学进展, 31(3), 6-14.]

Kano Y, Dudgeon D, Nam S, Samejima H, Watanabe K, Grudpan C, Grudpan J, Magtoon W, Musikasinthorn P, Nguyen PT, Praxaysonbath B, Sato T, Shibukawa K, Shimatani Y, Suvarnaraksha A, Tanaka W, Thach P, Tran DD, Yamashita T, Utsugi K (2016) Impacts of dams and global warming on fish biodiversity in the Indo-Burma hotspot. PLoS ONE, 11, e0160151.

Kottelat M (2000) Diagnoses of a new genus and 64 new species of fishes from Laos (Teleostei: Cyprinidae, Balitoridae, Bagridae, Syngnathidae, Chaudhuriidae and Tetraodontidae). Journal of South Asian Natural History, 5, 37-82. 
Kottelat M (2001) Fishes of Laos. Wildlife Heritage Trust Publications, pp. 1-198, Colombo.

Kottelat M (2009) Fishes of the upper Nam Ou drainage in Laos. WWF-Community Fisheries: Supporting food security and aquatic biodiversity (ComFish Project),

$1-27$.

Kottelat M (2016) The fishes of the Nam Theun and Xe Bangfai drainages, Laos. Hydroécologie Appliquée, 19, 271-320.

Kottelat M, Baroche RDL (2011) Fishes of the Xe Kong drainage in Laos, especially from the Xe Kaman. Co-Management of freshwater biodiversity in the Sekong Basin. WWF \& Critical Ecosystem Partnership Fund, 1-29.

Liu MD, Chen DQ, Duan XB, Wang K, Liu SP (2011) Ichthyofauna composition and distribution of fishes in Yunnan section of Lancang River. Journal of Fishery Sciences of China, 18, 156-170. (in Chinese with English abstract) [刘明典，陈大庆，段辛斌，王珂，刘绍平 (2011) 澜沧江云南段鱼类区系组成与分布. 中国 水产科学, 18, 156-170.]

Liu ZH, He JC, Jiang WG (1987) A survey of fishes in the middle reaches of the Lancang River, Yunnan Province. Journal of Yunnan University, 9, 146-150. (in Chinese with English abstract) [刘振华, 何纪昌, 江望高 (1987) 云南澜沧江中游地区鱼类调查研究. 云南大学学报, 9, 146-150.]

Ng NN, Kottelat M (2000) Descriptions of three new species of catfishes (Teleostei: Akysidae and Sisoridae) from Laos and Vietnam. Journal of South Asian Natural History, 5, 7-15.

Phomikong P, Fukushima M, Sricharoendham B, Nohara S, Jutagate T (2015) Diversity and community structure of fishes in the regulated versus unregulated tributaries of the Mekong River. River Research and Applications, 31, 1262-1275.

Valbo-Jørgensen J, Coates D, Hortle K (2009) Chapter 8-Fish diversity in the Mekong River Basin. The Mekong, 161-196.

Zheng LP, Chen XY, Yang XJ (2013) Status and conservation of fishes in the middle and lower Langcangjiang River. Zoological Research, 34, 680-686. (in Chinese with English abstract) [郑兰平，陈小勇，杨君兴 (2013) 澜沧江中下游鱼类现状及保护. 动物学研究, 34, 680-686.]

Zhou W, Li MH, Li YL (2016) Fish diversity in four nature reserves in Southwest Yunnan, China and the evaluation indicators. Biodiversity Science, 24, 313-320. (in Chinese with English abstract) [周伟, 李明会, 李有兰 (2016) 滇西南四个自然保护区鱼类多样性及评价指标探究. 生物多样性, 24, 313-320.]

Bureau of Aquatic Products, Tibet, China (1995) Fishes and Fish Resources in Xizang, China. China Agriculture Press, Beijing. [西藏自治区水产局 (1995) 西藏鱼 类及其资源. 中国农业出版社，北京.] 
李雪晴, 孙赫英, 何德奎, 陈毅峰. 澜沧江-涺公河中上游淡水鱼类多样性. 生物多样性, 2019, 27(10): 1090-1100. http://www.biodiversity-science.net/CN/10.17520/biods.2019195

附录2 澜沧江一泊公河中上游 32 个亚流域淡水鱼类物种名录

Appendix 2 List of freshwater fish species in 32 sub-basins of the upper and middle reaches of Lancang-Mekong River

物种

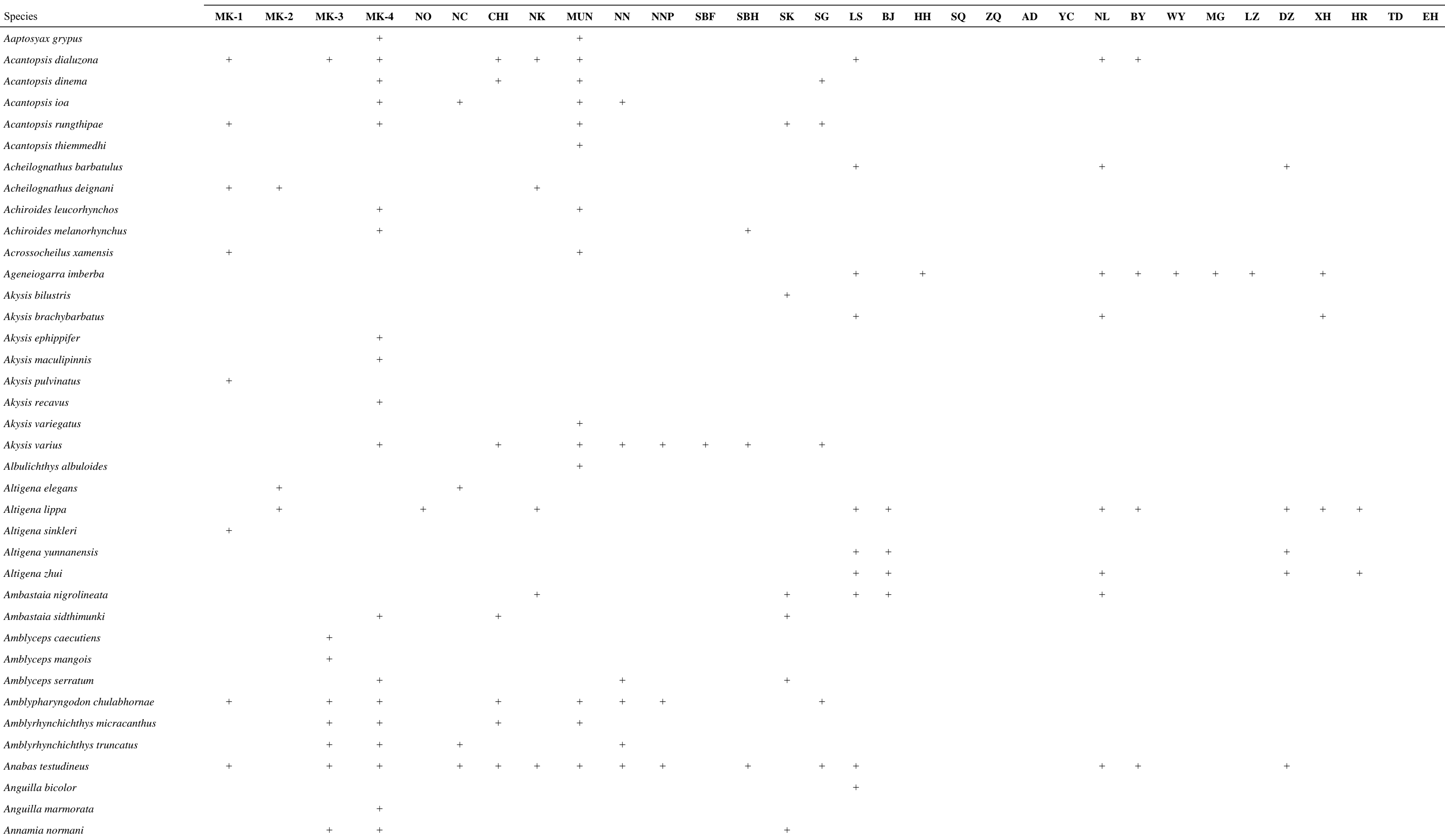

Annamia normani 
李雪晴, 孙赫英, 何德奎, 陈毅峰, 澜沧江一㯰公河中上游淡水鱼类多样性. 生物多样性, 2019, 27(10): 1090-1100. tt://www.biodiversity-science.net/CN/10.17520/biods.2019195

\begin{tabular}{|c|c|c|c|c|c|c|c|c|c|c|c|c|c|c|c|c|c|c|c|c|c|c|c|c|c|c|c|c|c|c|c|c|}
\hline 物种 & 亚流域 & 㐷 Sub-be & in codes & & & & & & & & & & & & & & & & & & & & & & & & & & & & & \\
\hline Species & MK-1 & MK-2 & MK-3 & MK-4 & No & $\mathrm{NC}$ & CHI & NK & MUN & NN & NNP & SBF & SBH & SK & SG & LS & BJ & HH & SQ & zQ & AD & YC & $\mathrm{NL}$ & BY & WY & MG & LZ & DZ & $\mathrm{XH}$ & HR & TD & EH \\
\hline Aperioptus delphax & + & & & + & & & & & + & & & & & & & & & & & & & & & & & & & & & & & \\
\hline Aperioptus gracilentus & + & & & + & + & & & + & + & & & & + & & & & & & & & & & & & & & & & & & & \\
\hline Aperioptus gracilis & & & & + & & & & & & & & & & & & + & & & & & & & + & + & & & & & & & & \\
\hline Aperioptus hapalias & & & + & + & + & & + & & + & + & + & + & + & & & & & & & & & & & & & & & & & & & \\
\hline Aplocheilus panchax & & & & & & & & & + & & & & & & & & & & & & & & & & & & & & & & & \\
\hline Arius acutirostris & & & & & & & & & & & & & + & & & & & & & & & & & & & & & & & & & \\
\hline Auriglobus modestus & & & + & & & & & & & & & & & & & & & & & & & & & & & & & & & & & \\
\hline Auriglobus nefastus & & & + & + & & + & & & + & + & & & & & & & & & & & & & & & & & & & & & & \\
\hline Badis ruber & + & + & & & & & & & & & & & & & & & & & & & & & & & & & & & & & & \\
\hline Bagarius bagarius & + & & + & + & + & + & & + & + & & + & & & & & & & + & & & & & + & + & + & & & & + & + & & \\
\hline Bagarius suchus & & & + & + & & + & & & + & & + & & & & & & & & & & & & & & & & & & & & & \\
\hline Bagarius yarrelli & + & + & + & + & + & + & & + & + & & + & & & & & + & & & & & & & + & + & + & & + & & + & & & \\
\hline Bagrichthys macracanthus & & & & & & & & & + & & & & & & & & & & & & & & & & & & & & & & & \\
\hline Bagrichthys macropterus & & & & & & & & & + & & & & & & & & & & & & & & & & & & & & & & & \\
\hline Bagrichthys majusculus & & & + & + & & & + & & + & & & & & & & & & & & & & & & & & & & & & & & \\
\hline Bagrichthys obscurus & & & & + & & & + & & + & & & & + & & & & & & & & & & & & & & & & & & & \\
\hline Balantiocheilos ambusticauda & & & & + & & & & & & & & & & & & & & & & & & & & & & & & & & & & \\
\hline Balantiocheilos melanopterus & + & + & + & + & & & & & & & & & & & & & & & & & & & & & & & & & & & & \\
\hline Balitora annamitica & & & & + & & & & & & & & & & & & & & & & & & & & & & & & & & & & \\
\hline Balitora kwangsiensis & & & & + & & & & & & & & & & & & & & & & & & & & & & & & & & & & \\
\hline Balitora lancangjiangensis & + & + & & + & + & & & + & + & & & & & & & + & & & & & & & + & + & & & + & & + & & & \\
\hline Balitoropsis vulgaris & + & & & & & & & & & & & & & & & + & + & & & & & & & & & & & & & & & \\
\hline Balitoropsis zollingeri & & & & + & & & & & & & & & & & & & & & & & & & & & & & & & & & & \\
\hline Bangana brevirostris & & & & & & & & & & & & & & & & & & & & & & & & + & + & & & & & & & \\
\hline Barbichthys laevis & + & & + & + & & & & & & & & & + & & + & & & & & & & & & & & & & & & & & \\
\hline Barbodes aurotaeniatus & & & + & + & & + & + & & + & + & + & + & + & + & & & & & & & & & & & & & & & & & & \\
\hline Barbodes binotatus & & & & + & & & & & + & & & & & & & & & & & & & & & & & & & & & & & \\
\hline Barbodes jacobusboehlkei & & & & + & & + & & & + & & & + & + & & & & & & & & & & & & & & & & & & & \\
\hline Barbodes lateristriga & & & & + & & & & & & & & & & & & & & & & & & & & & & & & & & & & \\
\hline Barbodes rhombeus & + & & & + & & & & & + & & & & & & & & & & & & & & & & & & & & & & & \\
\hline Barbonymus altus & + & & + & + & & + & + & & + & + & + & + & + & & & & & & & & & & & & & & & & & & & \\
\hline Barbonymus gonionotus & + & & + & + & & + & + & & + & & + & & + & & & & & & & & & & + & + & & & & & & & & \\
\hline Barbonymus schwanefeldii & + & & & + & & + & & & + & & & & & & & & & & & & & & & & & & & & & & & \\
\hline Barilius caudiocellatus & & & & & & & & & & & & & & & & & + & + & & & & & & & & + & + & & + & + & & \\
\hline Belodontichthys dinema & & & & & & & & & + & & & & & & & & & & & & & & & & & & & & & & & \\
\hline Belodontichthys truncatus & & & + & + & & & & & + & & & & + & & & & & & & & & & & & & & & & & & & \\
\hline Betta imbellis & & & & & & & & & + & & & & & & & & & & & & & & & & & & & & & & & \\
\hline Betta prima & & & & + & & & & & & & & & & & & & & & & & & & & & & & & & & & & \\
\hline Betta smaragdina & & & + & + & & & + & & + & + & + & & & & + & & & & & & & & & & & & & & & & & \\
\hline Betta splendens & + & & + & + & & & + & & + & & & & & & + & & & & & & & & & & & & & & & & & \\
\hline
\end{tabular}


李雪晴, 孙赫英, 何德奎, 陈毅峰, 澜沧江一㯰公河中上游淡水鱼类多样性. 生物多样性, 2019, 27(10): 1090-1100. tp://www.biodiversity-science.net/CN/10.17520/biods.2019195

\begin{tabular}{|c|c|c|c|c|c|c|c|c|c|c|c|c|c|c|c|c|c|c|c|c|c|c|c|c|c|c|c|c|c|c|c|c|}
\hline \multirow{2}{*}{$\begin{array}{l}\text { 物种 } \\
\text { Species }\end{array}$} & \multicolumn{32}{|c|}{ 亚流域代码 Sub-basin codes } \\
\hline & MK-1 & MK-2 & MK-3 & MK-4 & No & NC & CHI & NK & MUN & NN & NNP & SBF & SBH & SK & SG & LS & BJ & HH & sQ & $\mathbf{Z Q}$ & AD & YC & $\mathrm{NL}$ & BY & WY & MG & LZ & DZ & $\mathrm{XH}$ & HR & TD & EH \\
\hline Boesemania microlepis & & & & + & & & & & + & & + & & + & & & & & & & & & & & & & & & & & & & \\
\hline Boraras micros & & & & + & & & & & & + & & & & & & & & & & & & & & & & & & & & & & \\
\hline Boraras urophthalmoides & & & & + & & & & & & & & & & & & & & & & & & & & & & & & & & & & \\
\hline Brachirus harmandi & & & & + & + & + & + & + & + & + & + & + & + & & & & & & & & & & & & & & & & & & & \\
\hline Brachirus panoides & & & & & & & & & + & & & & & & & & & & & & & & & & & & & & & & & \\
\hline Brachirus siamensis & & & & + & & & & & + & & & & & & & & & & & & & & & & & & & & & & & \\
\hline Brachydanio rosea & & & & & + & & & + & & & & & & & & & & & & & & & & & & & & & & & & \\
\hline Brachygobius mekongensis & & & & + & & & & & + & + & & & + & & & & & & & & & & & & & & & & & & & \\
\hline Brachygobius xanthozona & & & & & & & + & & + & + & & & & & & & & & & & & & & & & & & & & & & \\
\hline Carassius praecipuus & & & & & & & & & & + & & & & & & & & & & & & & & & & & & & & & & \\
\hline Carinotetraodon lorteti & & & & & & & + & & + & & & & & & + & & & & & & & & & & & & & & & & & \\
\hline Catlocarpio siamensis & & & & + & & & & & & & & & & & & & & & & & & & & & & & & & & & & \\
\hline Cephalocassis borneensis & & & & + & & & & & & & & & & & & & & & & & & & & & & & & & & & & \\
\hline Ceratoglanis pachynema & & & & & & & & & + & & & & & & & & & & & & & & & & & & & & & & & \\
\hline Chagunius baileyi & + & & & & & & & & & & & & & & & & & & & & & & & & & & & & & & & \\
\hline Channa gachua & + & & + & + & + & + & + & + & + & + & + & + & + & + & + & + & & & & & & & + & + & + & & & + & + & + & & \\
\hline Channa limbata & + & + & & + & + & & & + & & + & & & & + & & & & & & & & & & & & & & & & & & \\
\hline Channa lucius & & & + & + & & & + & & + & + & & & + & & & + & & & & & & & & + & & & & & & & & \\
\hline Channa marulius & & & + & & & & & & & & & & & & & & & & & & & & & & & & & & & & & \\
\hline Channa melasoma & & & & & & & & & + & & & & & & & & & & & & & & & & & & & & & & & \\
\hline Channa micropeltes & + & & + & + & & & + & & + & & & & & & & & & & & & & & & & & & & & & & & \\
\hline Channa orientalis & & & + & + & & & & & & & & & & & & & & & & & & & & & & & & & & & & \\
\hline Channa striata & + & & + & + & + & + & + & + & + & + & + & + & + & & & + & & & & & & & + & & & & & & & & & \\
\hline Chaudhuria caudata & & & & + & & & + & & + & & & & + & & + & & & & & & & & & & & & & & & & & \\
\hline Chaudhuria fusipinnis & & & & & & & & & & & + & & & & & & & & & & & & & & & & & & & & & \\
\hline Chitala blanci & & & + & + & & & & & + & + & & & & & & & & & & & & & & & & & & & & & & \\
\hline Chitala chitala & + & & & + & & & & & & & & & & & & & & & & & & & & & & & & & & & & \\
\hline Chitala lopis & & & & & & & + & & & & & & & & & & & & & & & & & & & & & & & & & \\
\hline Chitala ornata & & & & + & & & & & + & + & & & & & & & & & & & & & & & & & & & & & & \\
\hline Cirrhinus cirrhosus & + & & + & + & + & & & + & + & & & & & & & & & & & & & & & & & & & & & & & \\
\hline Cirrhinus jullieni & + & & + & + & & & + & & + & & & & & + & & & & & & & & & & & & & & & & & & \\
\hline Cirrhinus microlepis & & & & + & & & & & + & & & & & & & & & & & & & & & & & & & & & & & \\
\hline Cirrhinus molitorella & + & & + & + & & & + & + & + & & & & & + & & + & & & & & & & + & + & & & & & + & & & \\
\hline Cirrhinus mrigala & & & + & & & & & & & & & & & & & & & & & & & & & & & & + & & & & & \\
\hline Cirrhinus prosemion & & & & + & + & & & & + & & & & + & & & & & & & & & & & & & & & & & & & \\
\hline Clarias batrachus & + & + & + & + & & + & + & + & + & & & + & + & & + & + & & & & & & & + & + & & & & & & & & \\
\hline Clarias fuscus & & & & & & & & & & & & & & + & & & & & & & & & & & & & & & & & & \\
\hline Clarias macrocephalus & + & & + & + & & + & + & & + & + & + & & + & & & & & & & & & & & & & & & & & & & \\
\hline Clarias meladerma & & & & + & & & & & + & & & & & & & & & & & & & & & & & & & & & & & \\
\hline Clarias serniosus & & & & + & & & & & & & & & & + & & & & & & & & & & & & & & & & & & \\
\hline
\end{tabular}


李雪晴, 孙赫英, 何德奎, 陈毅峰, 澜沧江一㯰公河中上游淡水鱼类多样性. 生物多样性, 2019, 27(10): 1090-1100. http://www.biodiversity-science.net/CN/10.17520/biods.2019195

\begin{tabular}{|c|c|c|c|c|c|c|c|c|c|c|c|c|c|c|c|c|c|c|c|c|c|c|c|c|c|c|c|c|c|c|c|c|}
\hline \multirow{2}{*}{$\begin{array}{l}\text { 物种 } \\
\text { Species }\end{array}$} & \multicolumn{32}{|c|}{ 亚流域代码 Sub-basin codes } \\
\hline & MK-1 & MK-2 & MK-3 & MK-4 & No & $\mathrm{NC}$ & CHI & NK & MUN & NN & NNP & SBF & SBH & SK & SG & LS & BJ & $\mathrm{HH}$ & SQ & $\mathbf{z Q}$ & AD & $\mathbf{Y C}$ & $\mathrm{NL}$ & BY & WY & MG & LZ & $\mathrm{DZ}$ & $\mathrm{xH}$ & HR & TD & EH \\
\hline Clupeichthys aesarnensis & & & + & + & + & & + & & + & + & + & + & + & & + & & & & & & & & & & & & & & & & & \\
\hline Clupeichthys goniognathus & & & + & + & & + & & & + & & & & & & & & & & & & & & & & & & & & & & & \\
\hline Clupeoides borneensis & & & & + & & + & & & & & & & + & & & & & & & & & & & & & & & & & & & \\
\hline Clupisoma longianale & & & & & & & & & & & & & & & & + & + & & & & & & & & & & + & & + & + & & \\
\hline Clupisoma sinense & & & & + & + & + & & & + & & & & & & & + & & + & & & & & + & + & & & + & & + & + & & \\
\hline Cobitis laoensis & & & & + & & & & & & & & & & & & & & & & & & & & & & & & & & & & \\
\hline Coilia lindmani & & & & & & & & & + & & & & & & & & & & & & & & & & & & & & & & & \\
\hline Coptodon zillii & + & & & & & & & & & & & & & & & & & & & & & & & & & & & & & & & \\
\hline Corica laciniata & & & + & & & & + & & + & & & & & & & & & & & & & & & & & & & & & & & \\
\hline Cosmochilus cardinalis & & & & & & & & & & & & & & & & + & & & & & & & + & + & & & & & + & + & & \\
\hline Cosmochilus harmandi & & & + & + & & + & + & & + & & + & & + & & & & & & & & & & & & & & & & & & & \\
\hline Creteuchiloglanis kamengensis & & & & & & & & & & & & & & & & & + & & + & & + & + & & & & & & & & & + & \\
\hline Creteuchiloglanis longipectoralis & & & & & & & & & & & & & & & & & + & & & & & & & & & & & & & & + & \\
\hline Crossocheilus atrilimes & + & & + & + & & & + & & + & + & + & + & + & & + & & & & & & & & & & & & & & & & & \\
\hline Crossocheilus cobitis & & & + & & & & & & & & & & & & & & & & & & & & & & & & & & & & & \\
\hline Crossocheilus oblongus & & & + & + & & & & & + & + & + & & & + & & & & & & & & & & & & & & & & & & \\
\hline Crossocheilus reticulatus & + & & + & + & & & + & & + & + & & & + & + & & + & & & & & & & & + & & & & & & & & \\
\hline Cyclocheilichthys apogon & + & & & + & & & + & + & + & + & + & & + & & & & & & & & & & & & & & & & & & & \\
\hline Cyclocheilichthys armatus & + & + & + & + & + & + & + & & + & + & & + & + & & + & & & & & & & & + & + & & & & & & & & \\
\hline Cyclocheilichthys heteronema & & & & + & & & & & + & & & & & & & & & & & & & & & & & & & & & & & \\
\hline Cyclocheilichthys lagleri & & & & + & & & & & & & & & & & & & & & & & & & & & & & & & & & & \\
\hline Cyclocheilichthys repasson & + & & + & + & + & + & + & + & + & + & + & + & + & & & + & & & & & & & + & + & & & & & & & & \\
\hline Cyclocheilos enoplos & & & & + & & & & & + & + & & & + & & + & & & & & & & & & & & & & & & & & \\
\hline Cyclocheilos furcatus & & & & + & & & & & + & & & & & & & & & & & & & & & & & & & & & & & \\
\hline Cynoglossus microlepis & & & & + & & & & & + & & & & & & & & & & & & & & & & & & & & & & & \\
\hline Cyprinus barbatus & & & & & & & & & & & & & & & & & & & & & & & & & & & & & & & & + \\
\hline Cyprinus chilia & & & & & & & & & & & & & & & & & & & & & & & & & & & & & & & & + \\
\hline Cyprinus daliensis & & & & & & & & & & & & & & & & & & & & & & & & & & & & & & & & + \\
\hline Cyprinus longipectoralis & & & & & & & & & & & & & & & & & & & & & & & & & & & & & & & & + \\
\hline Cyprinus megalophthalmus & & & & & & & & & & & & & & & & & & & & & & & & & & & & & & & & + \\
\hline Cyprinus pellegrini & & & & & & & & & & & & & & & & & & & & & & & & & & & & & & & & + \\
\hline Danio albolineatus & + & & + & + & & & & & + & & & & & & & & & & & & & & & & & & & & & & & \\
\hline Danio roseus & + & + & + & & + & & & + & & & & & & & & & & & & & & & & & & & & & & & & \\
\hline Datnioides microlepis & & & + & + & & & & & + & & & & + & & & & & & & & & & & & & & & & & & & \\
\hline Datnioides pulcher & & & & + & & & & & & & & & & & & & & & & & & & & & & & & & & & & \\
\hline Datnioides undecimradiatus & & & & + & & + & & & + & & & + & + & & & & & & & & & & & & & & & & & & & \\
\hline Dermogenys orientalis & & & & + & & & & & & & & & & & & & & & & & & & & & & & & & & & & \\
\hline Dermogenys pusilla & + & & & + & & & & & & & & & & & & & & & & & & & & & & & & & & & & \\
\hline Dermogenys siamensis & + & & + & + & & & & & + & & + & & & + & & & & & & & & & & & & & & & & & & \\
\hline Devario acrostomus & & & & & & & & & & & + & & & & & & & & & & & & & & & & & & & & & \\
\hline
\end{tabular}


李雪晴, 孙赫英, 何德奎, 陈毅峰, 澜沧江一㯰公河中上游淡水鱼类多样性. 生物多样性, 2019, 27(10): 1090-1100. htp://www.biodiversity-science.net/CN/10.17520/biods.2019195

\begin{tabular}{|c|c|c|c|c|c|c|c|c|c|c|c|c|c|c|c|c|c|c|c|c|c|c|c|c|c|c|c|c|c|c|c|c|}
\hline 物种 & 亚流域 & Sub-ba & in codes & & & & & & & & & & & & & & & & & & & & & & & & & & & & & \\
\hline Species & MK-1 & MK-2 & MK-3 & MK-4 & No & $\mathrm{NC}$ & CHI & NK & MUN & $\mathrm{NN}$ & NNP & SBF & SBH & SK & SG & LS & BJ & HH & SQ & zQ & AD & YC & $\mathrm{NL}$ & BY & WY & MG & LZ & DZ & $\mathrm{XH}$ & HR & TD & EH \\
\hline Devario aequipinnatus & & & & & & & & & & & & & & & & & & & & & & & & & & & + & & + & & & \\
\hline Devario annandalei & + & + & + & + & & & & & & & & & & & & & & & & & & & & & & & & & & & & \\
\hline Devario apopyris & + & & & & & & & & & & & & & & & & & & & & & & + & & & & & & & & & \\
\hline Devario browni & & & & & & & & & & & & & & & & & & & & & & & & & & & + & & + & & & \\
\hline Devario chrysotaeniatus & + & + & & & & + & & & & & & & & & & + & + & & & & & & + & + & & & & & & & & \\
\hline Devario fangfangae & & & & & & + & & & & + & & & & & & & & & & & & & & & & & & & & & & \\
\hline Devario gibber & & & & & & & & & & & & & & + & & & & & & & & & & & & & & & & & & \\
\hline Devario laoensis & + & & & & + & & & + & & + & & & + & & & & & & & & & & + & & & & & & & & & \\
\hline Devario leptos & + & + & & & & & & & & & & & & & & & & & & & & & & & & & & & & & & \\
\hline Devario regina & & & + & & & & & & & & & & & & & & & & & & & & & & & & & & & & & \\
\hline Devario salmonatus & & & & + & & & & & & & & & & + & & & & & & & & & & & & & & & & & & \\
\hline Dichotomyctere fluviatilis & + & + & + & + & & & & & & & & & & & & & & & & & & & & & & & & & & & & \\
\hline Discherodontus ashmeadi & + & & + & + & & & & & + & + & & & & + & & & & & & & & & & & & & & & & & & \\
\hline Discherodontus halei & + & + & + & + & & & & & & & & & & & & & & & & & & & & & & & & & & & & \\
\hline Discherodontus parvus & + & & & & & & & & & & & & & & & + & & & & & & & + & + & & & & & + & & & \\
\hline Doryichthys boaja & & & + & & & & & & & & & & & & & & & & & & & & & & & & & & & & & \\
\hline Doryichthys contiguus & & & & + & & & & & + & + & + & & & & & & & & & & & & & & & & & & & & & \\
\hline Doryichthys deokhatoides & & & & & & & & & & & & + & & & & & & & & & & & & & & & & & & & & \\
\hline Doryichthys martensii & & & & & & & & & + & & & & & & & & & & & & & & & & & & & & & & & \\
\hline Enteromius huguenyi & & & & & & & & & + & & & & & & & & & & & & & & & & & & & & & & & \\
\hline Epalzeorhynchos bicolor & & & & + & & & & & + & & & & & & & & & & & & & & & & & & & & & & & \\
\hline Epalzeorhynchos frenatum & + & & + & + & & & + & & + & + & & + & + & & & & & & & & & & & & & & & & & & & \\
\hline Epalzeorhynchos munense & & & + & + & & & & & + & & & & & + & & & & & & & & & & & & & & & & & & \\
\hline Esomus danrica & + & + & + & + & & & & & & & & & & & & & & & & & & & & & & & & & & & & \\
\hline Esomus longimanus & + & & + & + & & & + & & + & + & & & & & & & & & & & & & & & & & & & & & & \\
\hline Esomus metallicus & + & + & + & + & + & + & + & & + & + & & + & + & & & & & & & & & & & & & & & & & & & \\
\hline Eugnathogobius siamensis & & & & + & & & + & & + & & & & & & & & & & & & & & & & & & & & & & & \\
\hline Fluvitrygon signifer & + & & + & & & & & & & & & & & & & & & & & & & & & & & & & & & & & \\
\hline Folifer brevifilis & & & & & + & & & & & & & & & & & + & & & & & & & + & + & & & & & & & & \\
\hline Garra cambodgiensis & + & + & + & + & + & + & + & + & + & & + & & + & + & & + & & & & & & & & + & & & & & & & & \\
\hline Garra cryptonemus & & & & & & & & & & & & & & & & & + & & & & & & & & & & & & & & & \\
\hline Garra cyclostomata & + & + & + & + & & & & & & & & & & & & & & & & & & & & & & & & & & & & \\
\hline Garra cyrano & & & & & & & & & & & + & & & & & & & & & & & & & & & & & & & & & \\
\hline Garra fasciacauda & + & + & + & + & + & & & + & + & & & & + & & & + & & & & & & & + & & & & & & & & & \\
\hline Garra fuliginosa & + & + & & & & & & & & & & & & & & & & & & & & & & & & & & & & & & \\
\hline Garra mirofrontis & & & & & & & & & & & & & & & & + & + & + & & & & & + & + & + & & & + & & + & & \\
\hline Garra nasuta & & & & & & & & & + & & & & & & & & & & & & & & & & & & & & & & & \\
\hline Garra orientalis & & & & & & & & & & & & & & & & + & + & & & & & & & & + & & & & & & & \\
\hline Garra theunensis & & + & & & + & + & & & & & & & & & & & & & & & & & & & & & & & & & & \\
\hline Glossogobius aureus & & & & + & & & & & & & & & & & & & & & & & & & & & & & & & & & & \\
\hline
\end{tabular}


李雪晴, 孙赫英, 何德奎, 陈毅峰, 澜沧江一㯰公河中上游淡水鱼类多样性. 生物多样性, 2019, 27(10): 1090-1100. http://www.biodiversity-science.net/CN/10.17520/biods.2019195

\begin{tabular}{|c|c|c|c|c|c|c|c|c|c|c|c|c|c|c|c|c|c|c|c|c|c|c|c|c|c|c|c|c|c|c|c|c|}
\hline \multirow{2}{*}{$\begin{array}{l}\text { 物种 } \\
\text { Species }\end{array}$} & \multicolumn{32}{|c|}{ 亚流域代码 Sub-basin codes } \\
\hline & MK-1 & MK-2 & MK-3 & MK-4 & No & $\mathrm{NC}$ & CHI & NK & MUN & NN & NNP & SBF & SBH & SK & SG & LS & BJ & нH & SQ & $\mathbf{z Q}$ & AD & YC & $\mathrm{NL}$ & BY & WY & MG & LZ & DZ & $\mathrm{XH}$ & HR & TD & EH \\
\hline Glossogobius giuris & & & & + & & & & & & & & & & & & & & & & & & & & & & & & & & & & \\
\hline Glossogobius koragensis & & & & + & & & & & & & & & & & & & & & & & & & & & & & & & & & & \\
\hline Glyptothorax buchanani & + & & & & & & & & & & & & & & & & & & & & & & & & & & & & & & & \\
\hline Glyptothorax deqinensis & & + & & + & + & & & + & & & & & & & & & & & + & + & + & + & & & & & & & & & + & \\
\hline Glyptothorax forabilis & & & & & & & & & & & & & & + & & & & & & & & & & & & & & & & & & \\
\hline Glyptothorax fuscus & & & & & & & + & & + & & & & + & & & + & + & & & & & & & + & & & & & + & & & \\
\hline Glyptothorax honghensis & & & & & & + & & & & + & & & & & & & & & & & & & & & & & & & & & & \\
\hline Glyptothorax horai & + & & & & + & & & + & & & & & & & & + & + & + & & & & & + & + & + & & + & & & & & \\
\hline Glyptothorax lampris & & + & & + & + & & + & + & + & + & & & + & + & & + & & & & & & & + & + & & & & & + & + & & \\
\hline Glyptothorax laosensis & & + & & + & + & & & + & + & & & & + & + & & + & & + & & & & & + & + & + & + & + & & + & & & \\
\hline Glyptothorax longinema & & & & & & & & & & & & & & & & & + & + & & & + & + & & & & & + & & & & & \\
\hline Glyptothorax macromaculatus & & & & & & & & & & & & & & & & & & + & & & & & + & + & + & & + & & + & & & \\
\hline Glyptothorax major & + & + & + & + & & & & & & & & & & & & & & & & & & & & & & & & & & & & \\
\hline Glyptothorax platypogonides & & & & + & & & & & & & & & & & & & & & & & & & & & & & & & & & & \\
\hline Glyptothorax porrectus & & & & & & & & & & & & & & + & & & & & & & & & & & & & & & & & & \\
\hline Glyptothorax trilineatus & + & & & & & & & & & & & & & & & & & & & & & & & & & & & & & & & \\
\hline Glyptothorax zanaensis & & & & + & & & & & & & & & & & & & + & + & + & & & + & + & + & + & & & & & & + & \\
\hline Gobiobotia yuanjiangensis & & & & & & & & & & & & & & & & & & & & & & & & & & & + & & + & & & \\
\hline Gobiopterus chuno & & & & + & & & + & & + & & & & + & & + & & & & & & & & & & & & & & & & & \\
\hline Gymnocypris firmispinata & & & & & & & & & & & & & & & & & & & & & & + & & & & & & & & & & \\
\hline Gymnocypris potanini & & & & & & & & & & & & & & & & & & & + & & & + & & & & & & & & & + & \\
\hline Gymnodanio strigatus & & & & & & & & & & & & & & & & & & & & & & & & & + & & & & + & & & \\
\hline Gyrinocheilus aymonieri & + & & + & & & & + & & + & + & + & & & + & & + & & & & & & & + & + & & & & & & & & \\
\hline Gyrinocheilus pennocki & + & & & + & & & & & & & & & & & & & & & & & & & & & & & & & & & & \\
\hline Hampala dispar & + & & + & + & & + & + & + & + & + & + & + & + & & + & & & & & & & & & & & & & & & & & \\
\hline Hampala macrolepidota & + & + & + & + & + & + & + & + & + & + & + & & + & + & & & & & & & & & + & + & & & & & & & & \\
\hline Haplochromis niloticus & & & & + & & & & & & & & & & & & & & & & & & & & & & & & & & & & \\
\hline Helicophagus leptorhynchus & & & + & + & & + & + & & + & & & & + & & & & & & & & & & & & & & & & & & & \\
\hline Helicophagus waandersii & & & & + & & & & & + & & & & & & & & & & & & & & & & & & & & & & & \\
\hline Hemiarius verrucosus & & & & + & & & & & & & & & & & & & & & & & & & & & & & & & & & & \\
\hline Hemibagrus filamentus & + & & & + & & & + & & + & + & + & & + & & & & & & & & & & & & & & & & & & & \\
\hline Hemibagrus guttatus & & & & + & & & & & & & & & & & & & & & & & & & & & & & & & & & & \\
\hline Hemibagrus microphthalmus & & & & + & & & & & & & & & & & & & & & & & & & & & & & & & & & & \\
\hline Hemibagrus nетиrus & + & & + & + & & & + & & + & + & + & + & + & + & & + & & & & & & & + & + & & & & & & & & \\
\hline Hemibagrus planiceps & + & + & + & + & & & & & & & & & & & & & & & & & & & & & & & & & & & & \\
\hline Hemibagrus pluriradiatus & + & + & + & + & & & & & & & & & & & & & & & & & & & & & & & & & & & & \\
\hline Hemibagrus spilopterus & & & & + & & + & & & & & + & & + & & + & & & & & & & & & & & & & & & & & \\
\hline Hemibagrus wyckii & & & & + & & & & & + & & & & & & & & & & & & & & & & & & & & & & & \\
\hline Hemibagrus wyckioides & + & & & + & + & & + & + & + & + & & & & + & & & & & & & & & + & + & & & & & & & & \\
\hline Hemibarbus labeo & + & + & & & & + & & & & & & & & & & & & & & & & & & & & & & & & & & \\
\hline
\end{tabular}


李雪晴, 孙赫英, 何德奎, 陈毅峰, 澜沧江一㯰公河中上游淡水鱼类多样性. 生物多样性, 2019, 27(10): 1090-1100. htp://www.biodiversity-science.net/CN/10.17520/biods.2019195

\begin{tabular}{|c|c|c|c|c|c|c|c|c|c|c|c|c|c|c|c|c|c|c|c|c|c|c|c|c|c|c|c|c|c|c|c|c|}
\hline \multirow{2}{*}{$\begin{array}{l}\text { 物种 } \\
\text { Species }\end{array}$} & \multicolumn{32}{|c|}{ 亚流域代码 Sub-basin codes } \\
\hline & MK-1 & MK-2 & MK-3 & MK-4 & No & $\mathrm{NC}$ & CHI & NK & MUN & NN & NNP & SBF & SBH & SK & SG & LS & BJ & HH & sQ & $\mathbf{z Q}$ & AD & $\mathbf{Y C}$ & $\mathrm{NL}$ & BY & WY & MG & LZ & DZ & $\mathrm{xH}$ & HR & TD & EH \\
\hline Hemibarbus maculatus & & & & & + & & & + & & & & & & & & & & + & & & & & + & + & + & & + & & + & & & \\
\hline Hemibarbus medius & & + & & & & & & + & & & & & & & & + & & & & & & & & & & & & & & & & \\
\hline Hemiculterella macrolepis & + & + & & & + & + & & + & & & & & & & & & & & & & & & + & & & & & & & & & \\
\hline Hemigobius hoevenii & & & + & & & & & & & & & & & & & & & & & & & & & & & & & & & & & \\
\hline Hemimyzon confluens & & & & & & & & & & + & & & & & & & & & & & & & & & & & & & & & & \\
\hline Hemimyzon elongatus & & & & & & & & & & & & & & & & & & + & & & & & + & & + & + & + & & + & & & \\
\hline Hemimyzon khonensis & & & & + & & & & & & & & & & & & & & & & & & & & & & & & & & & & \\
\hline Hemimyzon papilio & & & & & + & + & & & & & & & & & & & & & & & & & & & & & & & & & & \\
\hline Hemimyzon pengi & + & + & & & + & & & + & & & & & & & & + & & & + & & & & + & + & & & & & & & & \\
\hline Hemimyzon tchangi & & & & & & & & & & & & & & & & + & + & + & + & & & + & & & & & & & & & + & \\
\hline Hemisilurus heterorhynchus & & & & & & & & & & & & & & & & + & & & & & & & + & + & & & & & & & & \\
\hline Hemisilurus mekongensis & & & + & + & & & & & + & & & & + & & & + & & & & & & & & & & & & & & & & \\
\hline Hemitrygon laosensis & + & & + & + & & & & & & & & & & & & & & & & & & & & & & & & & & & & \\
\hline Henicorhynchus caudimaculatus & & & + & + & & & + & & + & & & & & & & & & & & & & & & & & & & & & & & \\
\hline Henicorhynchus cryptopogon & & & & + & & & & & & & & & & & & & & & & & & & & & & & & & & & & \\
\hline Henicorhynchus lineatus & + & & + & + & & & + & & + & & & + & + & & & + & & & & & & & + & + & & & & & & & & \\
\hline Henicorhynchus lobatus & + & & + & + & + & & + & & + & + & + & + & + & & & & & & & & & & & & & & & & & & & \\
\hline Henicorhynchus ornatipinnis & + & & & + & & & & & + & + & + & & & & & & & & & & & & & & & & & & & & & \\
\hline Henicorhynchus siamensis & + & & + & + & & & + & & + & + & & & + & & + & & & & & & & & & & & & & & & & & \\
\hline Heteropneustes fossilis & + & & & & & & & & & & & & & & & & & & & & & & & & & & & & & & & \\
\hline Heteropneustes kemratensis & + & + & + & + & & & & & & & & & & & & & & & & & & & & & & & & & & & & \\
\hline Hilsa kelee & + & + & + & + & & & & & & & & & & & & & & & & & & & & & & & & & & & & \\
\hline Homaloptera confuzona & & & & & & & & & + & & & & & & & & & & & & & & & & & & & & & & & \\
\hline Homaloptera orthogoniata & & & + & + & & & & & & & & & & & & & & & & & & & & & & & & & & & & \\
\hline Homalopteroides smithi & + & & & + & & & & & + & + & + & & + & + & & & & & & & & & & & & & & & & & & \\
\hline Homalopteroides tweediei & + & & & + & + & & + & & + & & + & & & & & & & & & & & & & & & & & & & & & \\
\hline Homatula acuticephala & & & & & & & & & & & & & & & & & & & & & & & & & & & & & & & & + \\
\hline Homatula anguillioides & & & & & & & & & & & & & & & & & + & + & + & + & & & & & & & + & & + & & & + \\
\hline Homatula pycnolepis & & & & & & & & & & & & & & & & & + & + & & & & & & & & & & & & & & \\
\hline Homatula variegata & & & & & & & & & & & & & & & & & + & & & & & & & & & & & & & & & \\
\hline Homatula wuliangensis & & & & & & & & & & & & & & & & & & & & & & & & & & + & + & & & & & \\
\hline Hуроstomиs plecostomиs & & & + & & & & & & & & & & & & & & & & & & & & & & & & & & & & & \\
\hline Hypsibarbus huguenini & & & & + & & & & & & & & & & & & & & & & & & & & & & & & & & & & \\
\hline Hypsibarbus lagleri & & & & + & + & & & & + & & & & & & & & & & & & & & & & & & & & & & & \\
\hline Hypsibarbus malcolmi & + & & + & + & + & + & + & + & + & + & + & + & + & & & & & & & & & & & & & & & & & & & \\
\hline Hypsibarbus vernayi & + & + & & + & + & & & + & & + & & & + & + & & + & & & & & & & + & + & & & & & & & & \\
\hline Hypsibarbus wetmorei & + & + & + & + & & + & + & & + & & + & & + & & & & & & & & & & & & & & & & & & & \\
\hline Ilisha megaloptera & & & & & & & & & + & & & & & & & & & & & & & & & & & & & & & & & \\
\hline Incisilabeo behri & & & + & + & & & & & + & & & & & & & & & & & & & & & & & & & & & & & \\
\hline Indostomus crocodilus & + & + & + & + & & & & & & & & & & & & & & & & & & & & & & & & & & & & \\
\hline
\end{tabular}


李雪晴, 孙赫英, 何德奎, 陈毅峰, 澜沧江一㯰公河中上游淡水鱼类多样性. 生物多样性, 2019, 27(10): 1090-1100. http://www.biodiversity-science.net/CN/10.17520/biods.2019195

\begin{tabular}{|c|c|c|c|c|c|c|c|c|c|c|c|c|c|c|c|c|c|c|c|c|c|c|c|c|c|c|c|c|c|c|c|c|}
\hline 物种 & 亚流域 & 㐷 Sub-be & in codes & & & & & & & & & & & & & & & & & & & & & & & & & & & & & \\
\hline Species & MK-1 & MK-2 & MK-3 & MK-4 & No & $\mathrm{NC}$ & CHI & NK & MUN & NN & NNP & SBF & SBH & SK & SG & LS & BJ & HH & SQ & $\mathrm{zQ}$ & AD & $\mathbf{Y C}$ & $\mathrm{NL}$ & BY & wY & MG & LZ & DZ & $\mathrm{xH}$ & HR & TD & EH \\
\hline Indostomus paradoxus & + & + & + & + & & & & & & & & & & & & & & & & & & & & & & & & & & & & \\
\hline Indostomus spinosus & & & & + & & & + & & + & & + & & + & & & & & & & & & & & & & & & & & & & \\
\hline Kryptopterus bicirrhis & & & + & + & & & + & & + & & & & + & & & & & & & & & & & & & & & & & & & \\
\hline Kryptopterus cryptopterus & & & & + & & & & & + & & & & + & & & & & & & & & & & & & & & & & & & \\
\hline Kryptopterus dissitus & & & & + & & & & & & & & & & & & & & & & & & & & & & & & & & & & \\
\hline Kryptopterus geminus & & & + & + & & & + & & + & & & & + & & & & & & & & & & & & & & & & & & & \\
\hline Kryptopterus limpok & + & + & + & + & & & & & & & & & & & & & & & & & & & & & & & & & & & & \\
\hline Kryptopterus macrocephalus & + & + & + & + & & & & & & & & & & & & & & & & & & & & & & & & & & & & \\
\hline Kryptopterus palembangensis & + & + & + & + & & & & & & & & & & & & & & & & & & & & & & & & & & & & \\
\hline Kryptopterus schilbeides & & & & & & & & & & & & + & & & & & & & & & & & & & & & & & & & & \\
\hline Labeo barbatulus & & & + & & & & & & & & & & & & & & & & & & & & & & & & & & & & & \\
\hline Labeo calbasu & & & & & & & & & + & & & & & & & & & & & & & & & & & & & & & & & \\
\hline Labeo catla & & & & & & & & & + & & & & & & & & & & & & & & & & & & & & & & & \\
\hline Labeo chrysophekadion & + & & + & + & & & + & & + & + & + & & + & & + & & & & & & & & & & & & & & & & & \\
\hline Labeo dyocheilus & & & + & + & & & & & + & & & & & & & & & & & & & & & & & & & & & & & \\
\hline Labeo erythropterus & & & & + & & & & & & + & & & & & & & & & & & & & & & & & & & & & & \\
\hline Labeo indramontri & & & & + & & & & & & & & & & & & & & & & & & & & & & & & & & & & \\
\hline Labeo kawrus & + & + & + & + & & & & & & & & & & & & & & & & & & & & & & & & & & & & \\
\hline Labeo pierrei & & & & & & & & & & & & & & & & + & + & & & & & & + & + & & & & & + & + & & \\
\hline Labeo rohita & & & + & + & & & & & & & & & & & & & & & & & & & & & & & & & & & & \\
\hline Labiobarbus fasciatus & + & + & + & + & & & & & & & & & & & & & & & & & & & & & & & & & & & & \\
\hline Labiobarbus leptocheilus & + & & + & + & + & & + & & + & + & + & + & + & & + & + & & & & & & & & & & & & & & & & \\
\hline Labiobarbus lineatus & + & & + & + & & + & + & & + & + & & + & & & & + & & & & & & & + & + & & & & & + & & & \\
\hline Labiobarbus siamensis & + & & & + & & & & & + & & & & & & & & & & & & & & & & & & & & & & & \\
\hline Laides hexanema & & & & + & & & & & + & & & & & & & & & & & & & & & & & & & & & & & \\
\hline Laides longibarbis & & & + & + & + & & + & & + & & & & + & & & & & & & & & & & & & & & & & & & \\
\hline Laocypris hispida & & & & & & + & & & & + & & & & & & & & & & & & & & & & & & & & & & \\
\hline Laubuka caeruleostigmata & & & & + & & & & & + & & & & & & & & & & & & & & & & & & & & & & & \\
\hline Laubuka laubuca & & & & + & & & & & & & & & & & & & & & & & & & & & & & & & & & & \\
\hline Leiodon cutcutia & & & & & & & & & + & & & & & & & & & & & & & & & & & & & & & & & \\
\hline Lepidocephalichthys berdmorei & + & & & & + & & & + & & & & & & & & + & & & & & & & + & & & & & & & & & \\
\hline Lepidocephalichthys furcatus & + & & & & & & & & & & & & & & & & & & & & & & & & & & & & & & & \\
\hline Lepidocephalichthys hasselti & + & & + & + & & + & + & & + & + & + & & + & & + & + & & & & & & & + & + & & & & & + & & & \\
\hline Lepidocephalichthys kranos & & & & & & & + & & + & + & & & + & & & & & & & & & & & & & & & & & & & \\
\hline Lepidocephalichthys micropogon & & & & & & & + & & + & & & & & & & & & & & & & & & & & & & & & & & \\
\hline Lepidocephalichthys zeppelini & & & & + & & & + & & + & & & & & & & & & & & & & & & & & & & & & & & \\
\hline Lepidocephalus macrochir & & & & & & & & & & & & & & & & & & & & & & & & + & & & & & & & & \\
\hline Leptobarbus hoevenii & & & + & + & & & + & & + & & & & & & & & & & & & & & & & & & & & & & & \\
\hline Lobocheilos falcifer & & & & + & & & & & & & & & & & & & & & & & & & & & & & & & & & & \\
\hline Lobocheilos rhabdoura & + & & & + & & & + & & + & + & + & & + & + & & + & & & & & & & + & & & & & & + & & & \\
\hline
\end{tabular}


李雪晴, 孙赫英, 何德奎, 陈毅峰, 澜沧江一㯰公河中上游淡水鱼类多样性. 生物多样性, 2019, 27(10): 1090-1100. htp://www.biodiversity-science.net/CN/10.17520/biods.2019195

\begin{tabular}{|c|c|c|c|c|c|c|c|c|c|c|c|c|c|c|c|c|c|c|c|c|c|c|c|c|c|c|c|c|c|c|c|c|}
\hline \multirow{2}{*}{$\begin{array}{l}\text { 物种 } \\
\text { Species }\end{array}$} & \multicolumn{32}{|c|}{ 亚流域代码 Sub-basin codes } \\
\hline & MK-1 & MK-2 & MK-3 & MK-4 & No & $\mathrm{NC}$ & CHI & NK & MUN & NN & NNP & SBF & SBH & SK & SG & LS & BJ & HH & sQ & $\mathbf{z Q}$ & AD & $\mathbf{Y C}$ & $\mathrm{NL}$ & BY & WY & MG & LZ & DZ & $\mathrm{xH}$ & HR & TD & EH \\
\hline Longiculter siahi & & & & & & & + & & & & & & & & & & & & & & & & & & & & & & & & & \\
\hline Luciocyprinus striolatus & & & & & + & + & & & & & & & & & & + & & & & & & & + & + & & & & & & & & \\
\hline Luciosoma bleekeri & + & & + & + & & & + & & + & + & & & & & & & & & & & & & & & & & & & & & & \\
\hline Luciosoma setigerum & & & + & + & & & & & + & & & & + & & & & & & & & & & & & & & & & & & & \\
\hline Lycothrissa crocodilus & & & & + & & & & & & & & & & & & & & & & & & & & & & & & & & & & \\
\hline Macrochirichthys macrochirus & + & & + & & & & & & + & & & & & & & + & & & & & & & + & & & & & & & & & \\
\hline Macrognathus aculeatus & + & & & + & & & + & & + & & & & & & & & & & & & & & & & & & & & & & & \\
\hline Macrognathus circumcinctus & & & & + & & & + & & + & & & & & & & & & & & & & & & & & & & & & & & \\
\hline Macrognathus maculatus & + & + & + & + & & & & & & & & & & & & & & & & & & & & & & & & & & & & \\
\hline Macrognathus meklongensis & & & & & & & & & + & & & & & & & & & & & & & & & & & & & & & & & \\
\hline Macrognathus semiocellatus & & & & + & & + & + & & + & + & + & & & & & & & & & & & & & & & & & & & & & \\
\hline Macrognathus siamensis & + & + & + & + & & + & + & + & + & + & + & + & + & & + & & & & & & & & & & & & & & & & & \\
\hline Macropodus opercularis & & & & & & & & & & + & + & & & & & + & & & & & & & + & + & & & & & & & & + \\
\hline Mastacembelus armatus & + & + & + & + & + & + & + & + & + & + & + & + & + & + & + & + & & & & & & & + & + & & & + & & + & & & \\
\hline Mastacembelus erythrotaenia & & & & & & & + & & & & & & & & & & & & & & & & & & & & & & & & & \\
\hline Mastacembelus favus & + & & & + & & + & + & & + & + & & & & & + & & & & & & & & & & & & & & & & & \\
\hline Mastacembelus flavidus & & & & + & & & & & & & & & & & & & & & & & & & & & & & & & & & & \\
\hline Mekongina erythrospila & + & & + & + & & & & & + & & & & + & + & & & & & & & & & & & & & & & & & & \\
\hline Mekongina lancangensis & & & & & & & & & & & & & & & & & & & & & & & + & & & & & & & & & \\
\hline Metzia bounthobi & & & & & + & & & + & & & & & & & & & & & & & & & & & & & & & & & & \\
\hline Metzia lineata & + & & & & & & & & & & & & & & & & & & & & & & & & + & & & & & & & \\
\hline Microdevario kubotai & & & & & & & & & + & & & & & & & & & & & & & & & & & & & & & & & \\
\hline Micronema cheveyi & & & + & + & + & & + & & + & & & & + & & & + & & & & & & & + & + & & & & & & & & \\
\hline Micronema hexapterus & & & & & & & & & + & & & & & & & & & & & & & & & & & & & & & & & \\
\hline Misgurnus anguillicaudatus & & & & & & & & & & & & & & & & + & + & + & & & & & + & + & + & & + & & + & & & + \\
\hline Monopterus albus & + & & + & + & & + & + & & + & + & & & + & & & + & + & + & & & & & + & + & + & & + & & + & & & + \\
\hline Monopterus javanensis & + & & & + & & & + & + & + & + & & & + & & & & & & & & & & & & & & & & & & & \\
\hline Mustura bella & + & & & & & & & & & & & & & & & & & & & & & & & & & & & & & & & \\
\hline Mystacoleucus atridorsalis & + & & + & + & + & & + & + & + & & & + & + & + & + & & & & & & & & & & & & & & & & & \\
\hline Mystacoleucus chilopterus & + & & + & & & & & & + & & & & & & & + & & & & & & & + & + & + & & & & & & & \\
\hline Mystacoleucus ectypus & & & & + & & + & + & & + & + & + & & + & & & & & & & & & & & & & & & & & & & \\
\hline Mystacoleucus greenwayi & + & + & & + & + & + & & + & + & + & + & & + & & & & & & & & & & & & & & & & & & & \\
\hline Mystacoleucus lepturus & + & + & & & + & & & + & & + & + & & + & + & & + & & & & & & & + & + & + & & & & + & & & \\
\hline Mystacoleucus obtusirostris & + & + & + & + & + & + & + & + & + & + & + & + & + & & & + & & & & & & & + & & + & & & & + & + & & \\
\hline Mystus albolineatus & + & & & & & & + & & + & & + & & & & & & & & & & & & & & & & & & & & & \\
\hline Mystus atrifasciatus & + & & & + & & + & + & & + & + & + & + & + & & + & & & & & & & & & & & & & & & & & \\
\hline Mystus bocourti & & & + & + & & & + & & + & & & & & & + & & & & & & & & & & & & & & & & & \\
\hline Mystus cavasius & & & + & & & & + & & + & & & & & & & & & & & & & & & & & & & & & & & \\
\hline Mystus gulio & + & + & + & + & & & & & & & & & & & & & & & & & & & & & & & & & & & & \\
\hline Mystus multiradiatus & & & + & + & & & & & & & & & & & & & & & & & & & & & & & & & & & & \\
\hline
\end{tabular}


李雪晴, 孙赫英, 何德奎, 陈毅峰, 澜沧江一㯰公河中上游淡水鱼类多样性. 生物多样性, 2019, 27(10): 1090-1100. tt://www.biodiversity-science.net/CN/10.17520/biods.2019195

\begin{tabular}{|c|c|c|c|c|c|c|c|c|c|c|c|c|c|c|c|c|c|c|c|c|c|c|c|c|c|c|c|c|c|c|c|c|}
\hline 物种 & 亚流域 & 㐷 Sub-be & in codes & & & & & & & & & & & & & & & & & & & & & & & & & & & & & \\
\hline Species & MK-1 & MK-2 & MK-3 & MK-4 & No & $\mathrm{NC}$ & CHI & NK & MUN & $\mathrm{NN}$ & NNP & SBF & SBH & SK & SG & LS & BJ & HH & SQ & $\mathrm{ZQ}$ & AD & $\mathbf{Y C}$ & NL & BY & WY & MG & LZ & DZ & $\mathrm{xH}$ & HR & TD & EH \\
\hline Mystus mysticetus & & & + & + & & & + & & + & + & + & & + & & + & & & & & & & & & & & & & & & & & \\
\hline Mystus nigriceps & & & & + & & & + & & + & & & & & & & & & & & & & & & & & & & & & & & \\
\hline Mystus pelusius & & & & + & & & & & & & & & & & & & & & & & & & & & & & & & & & & \\
\hline Mystus rhegma & & & + & + & & & + & & + & & & + & + & & & & & & & & & & & & & & & & & & & \\
\hline Mystus singaringan & + & & & + & & + & + & & + & + & + & + & + & & + & & & & & & & & & & & & & & & & & \\
\hline Mystus velifer & + & + & + & + & & & & & & & & & & & & & & & & & & & & & & & & & & & & \\
\hline Mystus vittatus & & & & & & & & & + & & & & & & & & & & & & & & & & & & & & & & & \\
\hline Mystus wolffii & & & & & & & & & + & & & & & & & & & & & & & & & & & & & & & & & \\
\hline Nandus nandus & & & & & & & + & & & & & & + & & + & & & & & & & & & & & & & & & & & \\
\hline Nandus nebulosus & & & + & & & & & & & & & & & & & & & & & & & & & & & & & & & & & \\
\hline Nandus oxyrhynchus & & & + & + & & & + & & + & + & + & & + & & & & & & & & & & & & & & & & & & & \\
\hline Nemacheilus arenicolus & & & & & & + & & & & & & & & & & & & & & & & & & & & & & & & & & \\
\hline Nemacheilus binotatus & + & & & & & & & & & & & & & & & & & & & & & & & & & & & & & & & \\
\hline Nemacheilus longistriatus & + & & + & & & & & + & & & & + & + & + & & & & & & & & & & & & & & & & & & \\
\hline Nemacheilus masyae & & & & + & & & + & & & & & & & & & & & & & & & & & & & & & & & & & \\
\hline Nemacheilus pallidus & & & & + & & & + & & + & + & + & & + & & & & & & & & & & & & & & & & & & & \\
\hline Nemacheilus platiceps & + & & & + & & & & & + & + & + & + & + & & & & & & & & & & & & & & & & & & & \\
\hline Neodontobutis aurarmus & & & + & & & + & & & & & & & & & & & & & & & & & & & & & & & & & & \\
\hline Neolissochilus blanci & & & & + & & & & & & + & & & & & & & & & & & & & & & & & & & & & & \\
\hline Neolissochilus soro & & + & + & & & + & & & & & & + & & & & & & & & & & & & & & & & & & & & \\
\hline Neolissochilus stracheyi & & & & & & + & & & & + & & & & & & & & & & & & & & & & & & & & & & \\
\hline Neolissochilus vittatus & + & & & & & & + & & + & & & & & & & & & & & & & & & & & & & & & & & \\
\hline Neolissochilus wynaadensis & & & & & & & & & & & & & & & & & & & & & & & & & & & & & & + & & \\
\hline Neosalanx brevirostris & + & & & & + & & & & & & & & & & & & & & & & & & & & & & & & & & & \\
\hline Notopterus notopterus & + & & + & + & & & + & + & + & + & + & & + & & + & & & & & & & & & & & & & & & & & \\
\hline Ompok bimaculatus & & & + & + & & + & + & & + & + & + & + & + & & + & & & & & & & & & & & & & & & & & \\
\hline Ompok eugeneiatus & + & & & & & & & & & & & & & & & & & & & & & & & & & & & & & & & \\
\hline Ompok hypophthalmus & & & & + & & & & & & & & & & & & & & & & & & & & & & & & & & & & \\
\hline Ompok siluroides & & & & + & & & & & + & + & + & & + & & & & & & & & & & & & & & & & & & & \\
\hline Ompok urbaini & & & & + & & & & & & & & & & & & & & & & & & & & & & & & & & & & \\
\hline Onychostoma fangi & & & & & & & & & & & & & & & & + & & & & & & & + & + & & & & & & & & \\
\hline Onychostoma fusiforme & + & + & & & + & + & & & & & + & & & & & + & & & & & & & & & & & & & & & & \\
\hline Onychostoma gerlachi & + & + & & & + & & & + & & & & & + & & & + & & + & & & & & + & + & & & + & & + & & & \\
\hline Onychostoma lini & + & & + & & & & & & & & & & & & & & & & & & & & & & & & & & & & & \\
\hline Onychostoma meridionale & + & + & & + & + & & & + & & + & & & & + & & & & & & & & & & & & & & & & & & \\
\hline Onychostoma simum & & & & & & & + & & & & & & & & & & & & & & & & & & & & & & & & & \\
\hline Ophisternon bengalense & & & + & & & & & & + & & & & & & & & & & & & & & & & & & & & & & & \\
\hline Opsariichthys bidens & & & & & & & & & & & + & & & & & + & & + & & & & & + & + & + & & + & & + & & & \\
\hline Opsarius barna & + & + & + & + & & & & & & & & & & & & & & & & & & & & & & & & & & & & \\
\hline Opsarius karatensis & + & & & & & & & & & & & & & & & & & & & & & & & & & & & & & & & \\
\hline
\end{tabular}


李雪晴, 孙赫英, 何德奎, 陈毅峰, 澜沧江一㯰公河中上游淡水鱼类多样性. 生物多样性, 2019, 27(10): 1090-1100. ttp://www.biodiversity-science.net/CN/10.17520/biods.2019195

\begin{tabular}{|c|c|c|c|c|c|c|c|c|c|c|c|c|c|c|c|c|c|c|c|c|c|c|c|c|c|c|c|c|c|c|c|c|}
\hline 物种 & 亚流域 & 3 Sub-ba & in codes & & & & & & & & & & & & & & & & & & & & & & & & & & & & & \\
\hline Species & MK-1 & мK-2 & MK-3 & MK-4 & No & $\mathrm{NC}$ & CHI & NK & MUN & NN & NNP & SBF & SBH & SK & SG & LS & BJ & HH & SQ & $\mathbf{Z Q}$ & AD & YC & $\mathrm{NL}$ & BY & WY & MG & LZ & DZ & $\mathrm{XH}$ & HR & TD & EH \\
\hline Opsarius koratensis & + & + & + & + & + & & + & + & + & + & + & + & + & + & & & & & & & & & + & & & & & & & & & \\
\hline Opsarius ornatus & + & + & + & + & + & + & + & + & + & + & + & & & + & + & & & & & & & & + & + & & + & & & & & & \\
\hline Opsarius pulchellus & + & + & + & + & + & + & & + & + & & + & & + & + & & + & + & & & & & & + & + & + & & + & & + & + & & \\
\hline Oreichthys parvus & & & & & & & & & & + & + & & & & & & & & & & & & & & & & & & & & & \\
\hline Oreoglanis delacouri & & & & & & & & & & & + & & & & & & + & + & & & & & & & + & & & & + & & + & + \\
\hline Oreoglanis frenata & & & & & & & & & & & + & & & & & & & & & & & & & & & & & & & & & \\
\hline Oreoglanis hypsiura & & & & & & + & & & & & & & & & & & & & & & & & & & & & & & & & & \\
\hline Oreoglanis jingdongensis & & & & & & & & & & & & & & & & & + & & & & & & & & & + & & & + & & & \\
\hline Oreoglanis lepturus & & & & & & + & & & & & & & & & & & & & & & & & & & & & & & & & & \\
\hline Oreoglanis macronemus & & & & & & & & & & & + & & & & & & & & & & & & & & & & & & & & & \\
\hline Oreoglanis setigera & + & + & & & & & & & & & & & & & & & + & & + & + & & & & + & & & & & & & & \\
\hline Oreoglanis suraswadii & + & & & & & & & & & & & & & & & & & & & & & & & & & & & & & & & \\
\hline Oryzias javanicus & & & & + & & & & & & & & & & & & & & & & & & & & & & & & & & & & \\
\hline Oryzias latipes & & & & & & & & & & & & & & & & & & + & & & & & & + & + & & + & & & & & \\
\hline Oryzias mekongensis & & & + & + & & & + & & + & & & & + & & + & & & & & & & & & & & & & & & & & \\
\hline Oryzias minutillus & + & & & & & & + & & + & & & & & & & + & & & & & & & + & + & & & & & & & & \\
\hline Oryzias pectoralis & & & & & & + & & & & & & & & & & & & & & & & & & & & & & & & & & \\
\hline Oryzias sinensis & & & & + & & & & & & & & & & & & + & + & + & & & & & + & + & & & & & + & & & + \\
\hline Oryzias songkhramensis & & & & & & & & & & + & & & & & & & & & & & & & & & & & & & & & & \\
\hline Osphronemus exodon & & & & + & & & & & & & & & & + & & & & & & & & & & & & & & & & & & \\
\hline Osphronemus goramy & & & & & & & & & + & & & & & & & & & & & & & & & & & & & & & & & \\
\hline Osteochilus brachynotopteroides & & & & & & & & & & & & & & + & & & & & & & & & & & & & & & & & & \\
\hline Osteochilus enneaporos & + & + & + & + & & & & & & & & & & & & & & & & & & & & & & & & & & & & \\
\hline Osteochilus lini & & & & + & + & & + & & + & + & + & + & + & + & + & & & & & & & & & & & & & & & & & \\
\hline Osteochilus melanopleura & & & + & + & & & + & & + & + & & & + & & + & & & & & & & & & & & & & & & & & \\
\hline Osteochilus microcephalus & + & & + & + & & & + & & + & + & + & + & + & + & & & & & & & & & & & & & & & & & & \\
\hline Osteochilus schlegelii & & & & & & & + & & & & & & & & & & & & & & & & & & & & & & & & & \\
\hline Osteochilus striatus & & & & & & & & & & + & & + & & & & & & & & & & & & & & & & & & & & \\
\hline Osteochilus vittatus & + & & + & + & & + & + & & + & + & + & & + & + & + & & & & & & & & & & & & & & & & & \\
\hline Osteochilus waandersii & & & & + & & & & & & & + & + & & + & & & & & & & & & & & & & & & & & & \\
\hline Oxyeleotris marmorata & + & & + & + & & & + & & + & + & + & & + & & + & & & & & & & & & & & & & & & & & \\
\hline Oxygaster anomalura & & & & + & & & & & & & & & & & & & & & & & & & & & & & & & & & & \\
\hline Oxygaster pointoni & & & & & & & & & & & & & & & + & & & & & & & & & & & & & & & & & \\
\hline Pangasianodon gigas & + & + & + & + & & & & & & & & & & & & & & & & & & & & & & & & & & & & \\
\hline Pangasianodon hypophthalmus & + & & & + & & & & & + & & & & & & & & & & & & & & & & & & & & & & & \\
\hline Pangasius bocourti & & & & + & & & + & & + & & + & & + & & & & & & & & & & & & & & & & & & & \\
\hline Pangasius conchophilus & & & + & + & & & + & & + & & + & & & & & & & & & & & & & & & & & & & & & \\
\hline Pangasius djambal & & & & & & & & & & & & & & & & & & & & & & & & + & & & & & & & & \\
\hline Pangasius elongatus & & + & & & & & & & & & & & & & & & & & & & & & & & & & & & & & & \\
\hline Pangasius krempfi & & & & + & & & & & & & & & & & & & & & & & & & & & & & & & & & & \\
\hline
\end{tabular}


李雪晴, 孙赫英, 何德奎, 陈毅峰, 澜沧江一㯰公河中上游淡水鱼类多样性. 生物多样性, 2019, 27(10): 1090-1100. htp://www.biodiversity-science.net/CN/10.17520/biods.2019195

\begin{tabular}{|c|c|c|c|c|c|c|c|c|c|c|c|c|c|c|c|c|c|c|c|c|c|c|c|c|c|c|c|c|c|c|c|c|}
\hline \multirow{2}{*}{$\begin{array}{l}\text { 物种 } \\
\text { Species }\end{array}$} & \multicolumn{32}{|c|}{ 亚流域代码 Sub-basin codes } \\
\hline & MK-1 & MK-2 & MK-3 & MK-4 & No & $\mathrm{NC}$ & CHI & NK & MUN & $\mathrm{NN}$ & NNP & SBF & SBH & SK & SG & LS & BJ & HH & sQ & $\mathrm{zQ}$ & AD & YC & $\mathrm{NL}$ & BY & WY & MG & LZ & DZ & $\mathrm{xH}$ & HR & TD & EH \\
\hline Pangasius larnaudii & & & & + & & & & & + & & & & & & & & & & & & & & & & & & & & & & & \\
\hline Pangasius macronema & & & & + & + & + & + & & + & & + & & + & & + & & & & & & & & & & & & & & & & & \\
\hline Pangasius mekongensis & & & & + & & & & & + & & & & & & & & & & & & & & & & & & & & & & & \\
\hline Pangasius nasutus & & & + & & & & & & & & & & & & & & & & & & & & + & & & & & & & & & \\
\hline Pangasius pangasius & & & + & & & & & & & & & & & & & & & & & & & & & & & & & & & & & \\
\hline Pangasius polyuranodon & & & & & & & & & + & & & & & & & & & & & & & & & & & & & & & & & \\
\hline Pangasius sanitwongsei & & & + & + & & & & & + & & + & & + & & & & & & & & & & + & + & & & & & & & & \\
\hline Pangio anguillaris & + & & + & + & & & + & & + & & & & & + & + & & & & & & & & & & & & & & & & & \\
\hline Pangio fusca & & & & + & & & & & & & & & & & & & & & & & & & & & & & & & & & & \\
\hline Pangio longimanus & & & & & & & & & & & + & & & & & & & & & & & & & & & & & & & & & \\
\hline Pangio muraeniformis & + & + & + & + & & & & & & & & & & & & & & & & & & & & & & & & & & & & \\
\hline Pangio myersi & & & & + & & & & & & & & & & & & & & & & & & & & & & & & & & & & \\
\hline Pangio oblonga & & & & + & & & + & & + & & + & & + & & + & & & & & & & & & & & & & & & & & \\
\hline Pangio pangia & + & + & + & + & & & & & & & & & & & & & & & & & & & & & & & & & & & & \\
\hline Pangio piperata & & & & & & & & & & & & & & & + & & & & & & & & & & & & & & & & & \\
\hline Pao abei & & & & + & + & & & & + & & & & & & + & & & & & & & & & & & & & & & & & \\
\hline Pao baileyi & & & + & + & & & & + & + & & & & & & & & & & & & & & & & & & & & & & & \\
\hline Pao barbatus & & & + & + & & & & & + & & + & & & & & & & & & & & & & & & & & & & & & \\
\hline Pao brevirostris & & & + & + & & & & & & & & & & & & & & & & & & & & & & & & & & & & \\
\hline Pao cochinchinensis & & + & & + & + & & + & + & + & + & + & & & + & & & & & & & & & & & & & & & & & & \\
\hline Pao fangi & & & & & & & + & & + & & & & & & & & & & & & & & & & & & & & & & & \\
\hline Pao leiurus & + & & + & + & & + & + & & + & & & & + & + & + & + & & & & & & & + & & & & & & & & & \\
\hline Pao palembangensis & + & + & + & + & & & & & & & & & & & & & & & & & & & & & & & & & & & & \\
\hline Pao suvattii & & & + & + & & & + & & + & + & + & & + & & + & & & & & & & & & & & & & & & & & \\
\hline Pao turgidus & & + & & + & + & & & + & & & + & + & + & + & & & & & & & & & & & & & & & & & & \\
\hline Papuligobius ocellatus & + & + & + & + & + & & + & + & + & & + & + & + & + & & & & & & & & & & & & & & & & & & \\
\hline Paracanthocobitis botia & + & & & & & & & & & & & & & & & & & & & & & & & & & & & & & & & \\
\hline Parachela maculicauda & & & & + & & & + & & + & + & + & & & & & & & & & & & & & & & & & & & & & \\
\hline Parachela oxygastroides & + & & & + & & & + & & + & & & & & & & & & & & & & & & & & & & & & & & \\
\hline Parachela siamensis & & & & + & & & + & & + & + & & + & + & & & & & & & & & & & & & & & & & & & \\
\hline Parachela williaminae & & & & + & & & & & + & & & & & & & & & & & & & & & & & & & & & & & \\
\hline Paralaubuca barroni & + & & + & + & + & & & + & + & + & + & + & + & & & + & & & & & & & + & + & + & & & & + & + & & \\
\hline Paralaubuca harmandi & & & + & + & & & & & + & & & & & & & & & & & & & & & & & & & & & & & \\
\hline Paralaubuca riveroi & + & & & + & & & + & & + & & & & & & & & & & & & & & & & & & & & & & & \\
\hline Paralaubuca typus & + & & + & + & & & + & & + & & & + & + & & & & & & & & & & & & & & & & & & & \\
\hline Parambassis apogonoides & & & & + & & & & & + & & & & & & & & & & & & & & & & & & & & & & & \\
\hline Parambassis ranga & & & & + & & & + & & + & + & & & & & & & & & & & & & & & & & & & & & & \\
\hline Parambassis siamensis & + & & + & + & & + & + & + & + & & + & & + & + & + & & & & & & & & & & & & & & & & & \\
\hline Parambassis wolffii & & & + & + & & & + & + & + & & & & & & & & & & & & & & & & & & & & & & & \\
\hline Pareuchiloglanis abbreviata & & & & & & & & & & & & & & & & & & & & & & & & & & + & & + & & & & \\
\hline
\end{tabular}


李雪晴, 孙赫英, 何德奎, 陈毅峰, 澜沧江一㯰公河中上游淡水鱼类多样性. 生物多样性, 2019, 27(10): 1090-1100. http://www.biodiversity-science.net/CN/10.17520/biods.2019195

\begin{tabular}{|c|c|c|c|c|c|c|c|c|c|c|c|c|c|c|c|c|c|c|c|c|c|c|c|c|c|c|c|c|c|c|c|c|}
\hline 物种 & 亚流域 & 㐷 Sub-be & in codes & & & & & & & & & & & & & & & & & & & & & & & & & & & & & \\
\hline Species & MK-1 & MK-2 & MK-3 & MK-4 & No & NC & CHI & NK & MUN & NN & NNP & SBF & SBH & SK & SG & LS & BJ & HH & SQ & $\mathbf{Z Q}$ & AD & YC & $\mathrm{NL}$ & BY & WY & MG & LZ & DZ & $\mathrm{XH}$ & HR & TD & EH \\
\hline Pareuchiloglanis gracilicaudata & & & & & & & & & & & & & & & & & + & & + & + & + & + & & & & & & & & & + & \\
\hline Pareuchiloglanis myzostoma & & & & & & & & & & & & & & & & & + & & & + & & & & & & & & & & & + & \\
\hline Pareuchiloglanis prolixdorsalis & & & & & & & & & & & & & & & & & & & & & & & & & & & & & & + & & \\
\hline Percocypris retrodorsalis & & & & & & & & & & & & & & & & & + & + & & & & + & & & & & + & & + & & & + \\
\hline Pethia stoliczkana & + & & & & + & & & + & + & & & & & & & & & & & & & & & & & & & & & & & \\
\hline Pethia ticto & + & & & & & & & & & & & & & & & & & & & & & & + & & & & & & & & & \\
\hline Phalacronotus apogon & & & + & + & + & & + & & + & & + & + & + & & & & & & & & & & & & & & + & & & & & \\
\hline Phalacronotus bleekeri & & & + & + & & & & & + & & & & + & & & + & & & & & & & + & + & & & & & & & & \\
\hline Phalacronotus micronemus & & & & + & & & & & + & & & & & & & & & & & & & & & & & & & & & & & \\
\hline Phenacostethus smithi & & & & & & & & & + & & & & & & & & & & & & & & & & & & & & & & & \\
\hline Physoschistura pseudobrunneana & + & & & & & & & & & & & & & & & & & & & & & & & & & & & & & & & \\
\hline Physoschistura raoi & & & & & & & & & & & & & & & & & & & & & & & + & & & & & & & & & \\
\hline Physoschistura shuangjiangensis & & & & & & & & & & & & & & & & & + & & & & & & & & & & + & & + & & & \\
\hline Plotosus canius & & & & + & & & & & & & & & & & & & & & & & & & & & & & & & & & & \\
\hline Poecilia reticulata & & & + & + & & & & & & & & & & & & & & & & & & & & & & & & & & & & \\
\hline Polynemus aquilonaris & & & & + & & & & & & & & & & & & & & & & & & & & & & & & & & & & \\
\hline Polynemus dubius & & & & & & & & & + & & & & & & & & & & & & & & & & & & & & & & & \\
\hline Poropuntius angustus & + & + & & & + & & & & & & & & & & & & & & & & & & & & & & & & & & & \\
\hline Poropuntius bantamensis & + & & & & & & & & & & & & & & & & & & & & & & & & & & & & & & & \\
\hline Poropuntius bolovenensis & & & & + & & & & & & & & & & + & & & & & & & & & & & & & & & & & & \\
\hline Poropuntius carinatus & & & + & & + & + & & + & & + & & & & & & + & & & & & & & & & & & + & & + & + & & \\
\hline Poropuntius chondrorhynchus & + & & & & & & & & & & & & & & & & & & & & & & & & & & & & & & & \\
\hline Poropuntius cogginii & & & & & & & & & & & & & & & & & & & & & & & & & & & & & & & & + \\
\hline Poropuntius consternans & & & & + & & & & & & & & & & + & & & & & & & & & & & & & & & & & & \\
\hline Poropuntius deauratus & + & & + & + & & & & & + & + & & + & + & + & & & & & & & & & & & & & & & & & & \\
\hline Poropuntius exiguus & & & & & & & & & & & & & & & & & & & & & & & & & & & & & & & & + \\
\hline Poropuntius huangchuchieni & & & & & & & & & & & & & & & & + & + & + & & & & & + & + & + & + & + & + & & + & & \\
\hline Poropuntius krempfi & & & & & & & & & & & & & & & & & & & & & & & + & + & & & & & & & & \\
\hline Poropuntius laoensis & + & + & + & + & + & & & + & + & & + & & + & + & & & & & & & & & & & & & & & & & & \\
\hline Poropuntius lobocheiloides & & & & + & & & & & & & & & & + & & & & & & & & & & & & & & & & & & \\
\hline Poropuntius normani & & & & + & + & + & & + & + & + & + & & + & + & & & & & & & & & & & & & & & & & & \\
\hline Poropuntius solitus & & & & + & & & & & & & & & & + & & & & & & & & & & & & & & & & & & \\
\hline Poropuntius speleops & & & & & & & + & & & & & & & & & & & & & & & & & & & & & & & & & \\
\hline Pristis pristis & & & & + & & & & & & & & & & & & & & & & & & & & & & & & & & & & \\
\hline Pristolepis fasciata & + & & + & + & & + & + & & + & + & + & + & + & + & + & & & & & & & & & & & & & & & & & \\
\hline Probarbus jullieni & + & & + & + & + & + & & & + & & & & + & & & & & & & & & & & & & & & & & & & \\
\hline Probarbus labeamajor & & & & + & & & & & & & & & & & & & & & & & & & & & & & & & & & & \\
\hline Probarbus labeaminor & & & + & + & & & & & + & & & & & & & & & & & & & & & & & & & & & & & \\
\hline Pseudecheneis immaculata & & & & & & & & & & & & & & & & & & & + & & + & + & & & & & & & & & + & \\
\hline Pseudecheneis sulcata & & & & & & & & & & & & & & & & + & + & + & & + & & + & + & + & & & + & & + & & + & \\
\hline
\end{tabular}


李雪晴, 孙赫英, 何德奎, 陈毅峰, 澜沧江一㯰公河中上游淡水鱼类多样性. 生物多样性, 2019, 27(10): 1090-1100. htp://www.biodiversity-science.net/CN/10.17520/biods.2019195

\begin{tabular}{|c|c|c|c|c|c|c|c|c|c|c|c|c|c|c|c|c|c|c|c|c|c|c|c|c|c|c|c|c|c|c|c|c|}
\hline \multirow{2}{*}{$\begin{array}{l}\text { 物种 } \\
\text { Species }\end{array}$} & \multicolumn{32}{|c|}{ 亚流域代码 Sub-basin codes } \\
\hline & MK-1 & MK-2 & MK-3 & MK-4 & No & $\mathrm{NC}$ & CHI & NK & MUN & NN & NNP & SBF & SBH & SK & SG & LS & BJ & HH & SQ & $\mathrm{zQ}$ & AD & YC & NL & BY & WY & MG & LZ & $\mathrm{DZ}$ & $\mathrm{xH}$ & HR & TD & EH \\
\hline Pseudecheneis sulcatoides & & & & & & & & & & & & & & & & + & + & + & & & & + & & + & + & & + & & & + & & \\
\hline Pseudecheneis sympelvica & & & & & & & & + & & + & & & & & & & & & & & & & & & & & & & & & & \\
\hline Pseudobagarius inermis & + & & & + & + & & & + & & & & & + & + & & & & & & & & & & & & & & & & & & \\
\hline Pseudobagarius leucorhynchus & & & & & & & + & & & & & & & & & & & & & & & & & & & & & & & & & \\
\hline Pseudobagarius nitidus & & & & + & & & & & & & & & & & & & & & & & & & & & & & & & & & & \\
\hline Pseudobagarius sinensis & & & & & & & & & & & & & & & & + & & & & & & & + & + & & & & & & & & \\
\hline Pseudobagarius subtilis & & & + & + & & & & & & & & & & & & & & & & & & & & & & & & & & & & \\
\hline Pseudohemiculter dispar & + & & & & + & & & + & & & & & & & & & & & & & & & & & & & & & & & & \\
\hline Pseudohomaloptera leonardi & + & & & + & & & & & + & + & & & + & + & & & & & & & & & & & & & & & & & & \\
\hline Pseudohomaloptera sexmaculata & + & & & & & + & & & & & & & & & & & & & & & & & & & & & & & & & & \\
\hline Pseudohomaloptera yunnanensis & + & & & & & & & & & & & & & & & + & + & + & & + & & + & & & + & & & & + & & + & \\
\hline Pseudolais micronemus & & & & + & & & & & + & & & & & & & & & & & & & & + & + & & & & & & & & \\
\hline Pseudolais pleurotaenia & & & + & + & + & & & & + & & & & + & & & & & & & & & & & & & & & & & & & \\
\hline Pseudolaubuca sinensis & & & & & & & & & & & & & & & & + & & & & & & & & & & & & & & & & \\
\hline Pseudomystus bomboides & & & & & & & & & & & + & & & & & & & & & & & & & & & & & & & & & \\
\hline Pseudomystus siamensis & + & & + & + & + & & + & & + & + & & & & + & & & & & & & & & & & & & & & & & & \\
\hline Pterocryptis cochinchinensis & & & & & & + & & & & & & & & & & & & & & & & & & & & & & & & & & \\
\hline Pterocryptis inusitata & & & & & & + & & & & & & & & & & & & & & & & & & & & & & & & & & \\
\hline Pteronemacheilus meridionalis & + & + & & & + & & & & & + & & & & & & + & & & & & & & + & + & & & + & & & & & \\
\hline Ptychobarbus kaznakovi & & & & & & & & & & & & & & & & & & & + & + & & & + & & & & & & & & + & \\
\hline Puntigrus partipentazona & & & + & + & & & + & & + & + & + & & + & & + & & & & & & & & & & & & & & & & & \\
\hline Puntioplites falcifer & & & + & + & + & + & & & + & + & + & & + & & & & & & & & & & & + & & & & & & & & \\
\hline Puntioplites proctozysron & + & & + & + & & & + & & + & + & & + & + & & + & + & & & & & & & + & + & & & & & & & & \\
\hline Puntioplites waandersi & + & & + & & & & & & & & & & & & + & + & & & & & & & + & + & & & & & & & & \\
\hline Puntius brevis & + & + & + & + & & + & + & & + & + & + & + & + & & + & & & & & & & & & & & & & & & & & \\
\hline Puntius masyai & & & & & & & + & & + & + & & & + & & & & & & & & & & & & & & & & & & & \\
\hline Puntius semifasciolatus & & & & & & & & & + & & & & & & & + & & & & & & & + & + & & & & & & & & \\
\hline Puntius sophoroides & & & & & & & & & + & & & & & & & & & & & & & & & & & & & & & & & \\
\hline Raiamas guttatus & + & + & + & + & + & + & + & + & + & + & + & + & + & + & & + & & & & & & & + & + & + & & + & & + & & & \\
\hline Rasbora amplistriga & & & & & & & & & & & & & & + & & & & & & & & & & & & & & & & & & \\
\hline Rasbora argyrotaenia & & & + & & & & & & & & & & & & & & & & & & & & & & & & & & & & & \\
\hline Rasbora atridorsalis & & & & + & & & & & & + & & & & & & + & & & & & & & + & & & & & & & & & \\
\hline Rasbora aurotaenia & + & & + & + & & & + & & + & & & + & + & & + & & & & & & & & & & & & & & & & & \\
\hline Rasbora borapetensis & & & + & + & & + & + & & + & + & + & + & + & & + & & & & & & & & & & & & & & & & & \\
\hline Rasbora daniconius & & & + & + & & + & + & & + & + & & & & & + & & & & & & & & & & & & & & & & & \\
\hline Rasbora dorsinotata & + & + & & & & & & & & & & & & & & & & & & & & & & & & & & & & & & \\
\hline Rasbora dusonensis & + & & + & + & & & + & & + & + & + & + & + & & + & & & & & & & & & & & & & & & & & \\
\hline Rasbora hobelmani & + & + & & & + & & & & & & + & & & & & & & & & & & & & & & & & & & & & \\
\hline Rasbora lateristriata & + & + & + & + & & & & & & & & & & & & & & & & & & & & & & & & & & & & \\
\hline Rasbora myersi & + & & + & + & & & + & & + & & & & + & & & + & & & & & & & & + & & & & & & & & \\
\hline
\end{tabular}


李雪晴, 孙赫英, 何德奎, 陈毅峰, 澜沧江一㯰公河中上游淡水鱼类多样性. 生物多样性, 2019, 27(10): 1090-1100. tt://www.biodiversity-science.net/CN/10.17520/biods.2019195

\begin{tabular}{|c|c|c|c|c|c|c|c|c|c|c|c|c|c|c|c|c|c|c|c|c|c|c|c|c|c|c|c|c|c|c|c|c|}
\hline 物种 & 亚流域 & Sub-b & in codes & & & & & & & & & & & & & & & & & & & & & & & & & & & & & \\
\hline Species & MK-1 & MK-2 & MK-3 & MK-4 & No & NC & CHI & NK & MUN & NN & NNP & SBF & SBH & SK & SG & LS & BJ & HH & SQ & $\mathbf{z Q}$ & AD & $\mathbf{Y C}$ & $\mathrm{NL}$ & BY & WY & MG & LZ & DZ & $\mathrm{XH}$ & HR & TD & EH \\
\hline Rasbora paucisqualis & + & + & + & + & & & & & & & & & & & & & & & & & & & & & & & & & & & & \\
\hline Rasbora paviana & + & + & + & + & + & + & & & + & + & + & & + & + & & & & & & & & & & & & & & & & & & \\
\hline Rasbora rasbora & + & & & & & & & & & & & & & & & & & & & & & & & & & & & & & & & \\
\hline Rasbora rubrodorsalis & & & + & + & & & + & & + & + & + & & + & & & & & & & & & & & & & & & & & & & \\
\hline Rasbora septentrionalis & + & & & + & + & & & & & & & & & & & + & & & & & & & & & & & & & & & & \\
\hline Rasbora sumatrana & + & & & + & & & & & + & & & & & & & & & & & & & & & & & & & & & & & \\
\hline Rasbora tornieri & & & & + & & & & & & & & & & & & & & & & & & & & & & & & & & & & \\
\hline Rasbora trilineata & + & & + & + & & & + & & + & + & + & & + & & & & & & & & & & & & & & & & & & & \\
\hline Rasbosoma spilocerca & & & & + & & & + & & + & + & & & + & & + & & & & & & & & & & & & & & & & & \\
\hline Rhinogobius albimaculatus & + & & & & & & & & & + & & & & & & & & & & & & & & & & & & & & & & \\
\hline Rhinogobius brunneus & & & & & & & & & & & & & & & & + & & & & & & & + & + & & & & & + & & & \\
\hline Rhinogobius changjiangensis & + & & & & & & & & & & & & & & & & & & & & & & & & & & & & & & & \\
\hline Rhinogobius lineatus & & & & & & + & & & & & & & & & & & & & & & & & & & & & & & & & & \\
\hline Rhinogobius maculicervix & + & & + & & & & & & & & & & & & & + & & & & & & & & & & & & & & & & \\
\hline Rhinogobius mekongianus & + & + & + & + & + & + & & + & + & + & + & & & & + & & & & & & & & & & & & & & & & & \\
\hline Rhinogobius milleri & + & & & & & & & & & & & & & & & & & & & & & & & & & & & & & & & \\
\hline Rhinogobius taenigena & + & & & & & & & & & & & & & & & & & & & & & & & & & & & & & & & \\
\hline Rhodeus laoensis & & & & & & + & & & & & & & & & & & & & & & & & & & & & & & & & & \\
\hline Rhodeus ocellatus & & & & & & & & & & & & & & & & + & & & & & & & + & + & & & & & + & & & \\
\hline Rhodeus spinalis & & & & & & & & & & & & & & & & & & & & & & & + & & & & & & & & & \\
\hline Scaphiodonichthys acanthopterus & + & + & & & + & & & + & & + & & & & + & & + & & + & & & & & + & + & + & + & + & + & + & & & \\
\hline Scaphiodonichthys burmanicus & & & & & & & & & + & & & & & & & & & & & & & & & & & & & & & & & \\
\hline Scaphognathops bandanensis & & & + & + & + & + & & & + & + & + & + & + & + & & & & & & & & & & & & & & & & & & \\
\hline Scaphognathops stejnegeri & + & & + & + & + & + & & + & + & & + & & + & + & & & & & & & & & & & & & & & & & & \\
\hline Scaphognathops theunensis & & & & & & + & & & & & & & & & & & & & & & & & & & & & & & & & & \\
\hline Schistura amplizona & & + & & & + & & & & & & & & & & & & & & & & & & + & & & & & & & & & \\
\hline Schistura aramis & & & & & + & & & & & & & & & & & & & & & & & & & & & & & & & & & \\
\hline Schistura athos & & & & & + & & & & & & & & & & & & & & & & & & & & & & & & & & & \\
\hline Schistura atra & & & & & & + & & & & & & & & & & & & & & & & & & & & & & & & & & \\
\hline Schistura bairdi & & & & + & & & & & & & & & & & & & & & & & & & & & & & & & & & & \\
\hline Schistura bannaensis & & & & & & & & & & & & & & & & & & & & & & & + & & & & & & & & & \\
\hline Schistura bolavenensis & & & & & & & & & & & & & & + & & & & & & & & & & & & & & & & & & \\
\hline Schistura breviceps & + & & & & & & & & & & & & & & & & & & & & & & + & & & & & & & & & \\
\hline Schistura bucculenta & + & & & & + & & & + & & & + & & & & & + & & & & & & & + & + & & & & & & & & \\
\hline Schistura cataracta & & & & & & + & & & & & & + & & & & & & & & & & & & & & & & & & & & \\
\hline Schistura caudofurca & & & & & & & & + & & & & & & & & & & & & & & & & & & & & & & & & \\
\hline Schistura clatrata & & & & + & & & & & & & & & & + & & & & & & & & & & & & & & & & & & \\
\hline Schistura colossa & & & & + & & & & & & & & & & + & & & & & & & & & & & & & & & & & & \\
\hline Schistura conirostris & & & & & + & & & & & & & & & & & + & & & & & & & + & + & & & & & & & & \\
\hline Schistura coruscans & & & & & & & & & & + & & & & & & & & & & & & & & & & & & & & & & \\
\hline
\end{tabular}


李雪晴, 孙赫英, 何德奎, 陈毅峰, 澜沧江一㯰公河中上游淡水鱼类多样性. 生物多样性, 2019, 27(10): 1090-1100. htp://www.biodiversity-science.net/CN/10.17520/biods.2019195

\begin{tabular}{|c|c|c|c|c|c|c|c|c|c|c|c|c|c|c|c|c|c|c|c|c|c|c|c|c|c|c|c|c|c|c|c|c|}
\hline \multirow{2}{*}{$\begin{array}{l}\text { 物种 } \\
\text { Species }\end{array}$} & \multicolumn{32}{|c|}{ 亚流域代码 Sub-basin codes } \\
\hline & MK-1 & MK-2 & MK-3 & MK-4 & No & NC & CHI & NK & MUN & $\mathrm{NN}$ & NNP & SBF & SBH & SK & SG & LS & BJ & HH & SQ & $\mathrm{zQ}$ & AD & $\mathbf{Y C}$ & $\mathrm{NL}$ & BY & WY & MG & LZ & $\mathrm{DZ}$ & $\mathrm{xH}$ & HR & TD & EH \\
\hline Schistura crabro & & & & & & & & & & & + & & & & & & & & & & & & & & & & & & & & & \\
\hline Schistura cryptofasciata & & & & & & & & & & & & & & & & & & & & & & & & & & & & & + & & & \\
\hline Schistura daubentoni & & & & & & & & & & & & + & & & & & & & & & & & & & & & & & & & & \\
\hline Schistura defectiva & & & & & & & & & & + & & & & & & & & & & & & & & & & & & & & & & \\
\hline Schistura dorsizona & & & & & & + & & & & + & & & & & & & & & & & & & & & & & & & & & & \\
\hline Schistura ephelis & & & & & & & & + & & + & & & & & & & & & & & & & & & & & & & & & & \\
\hline Schistura epixenos & & & & & & & & & & & & + & & & & & & & & & & & & & & & & & & & & \\
\hline Schistura fasciolata & & & & & & & & & & & & & & & & & + & + & & & & & + & + & + & & + & & + & & & \\
\hline Schistura fusinotata & & & & & & & & & & & & & & + & & & & & & & & & & & & & & & & & & \\
\hline Schistura globiceps & & + & & & & & & & & & & & & & & & & & & & & & & & & & & & & & & \\
\hline Schistura imitator & & & & & & & & & & & & & & + & & & & & & & & & & & & & & & & & & \\
\hline Schistura irregularis & & & & & & & & + & & & & & & & & & & & & & & & & & & & & & & & & \\
\hline Schistura isostigma & & + & & & & & & & & + & + & & & & & & & & & & & & & & & & & & & & & \\
\hline Schistura kaysonei & & & & & & + & & & & & & & & & & & & & & & & & & & & & & & & & & \\
\hline Schistura kengtungensis & + & & & & & & & & & & & & & & & + & + & & & & & & + & & & & + & & + & & & \\
\hline Schistura khamtanhi & & & & + & & & & & & & & & & + & & & & & & & & & & & & & & & & & & \\
\hline Schistura kloetzliae & + & & & & & & & & & & & & & & & & & & & & & & + & & & & & & & & & \\
\hline Schistura klydonion & & & & & & & & & & & & & & + & & & & & & & & & & & & & & & & & & \\
\hline Schistura kohchangensis & & & & & & & & & + & & & & & & & & & & & & & & & & & & & & & & & \\
\hline Schistura kongphengi & & & & & & + & & & & & & + & + & + & & & & & & & & & & & & & & & & & & \\
\hline Schistura laterimaculata & & & & & & & + & & & & & & & & & & & & & & & & & & & & & & & & & \\
\hline Schistura latidens & & & & & & & & & & & & & + & & & & & & & & & & & & & & & & & & & \\
\hline Schistura latifasciata & & + & & & & & & & & & & & & & & & & + & & & & & + & & & & + & & + & & & \\
\hline Schistura leukensis & & & + & + & & & & & & & + & & & & & & & & & & & & & & & & & & & & & \\
\hline Schistura longa & & & + & & & & & & & + & & & & & & & & & & & & & & & & & & & & & & \\
\hline Schistura macrocephalus & + & & & & & & & & & & & & & & & & & & & & & & + & & & & & & & & & \\
\hline Schistura magnifluvis & + & & + & & + & & & & & & & & & & & & & & & & & & & & & & & & & & & \\
\hline Schistura melarancia & + & + & & & + & & & + & & & & & & & & & & & & & & & & & & & & & & & & \\
\hline Schistura menanensis & & & & + & & & & & & & & & & & & & & & & & & & & & & & & & & & & \\
\hline Schistura nasifilis & + & + & + & & & & & & & + & & & & & & & & & & & & & & & & & & & & & & \\
\hline Schistura nicholsi & + & + & + & & + & & & + & & + & & & & & & + & & & & & & & + & + & & & & & + & & & \\
\hline Schistura nomi & & & & & & & & & & & & & & + & & & & & & & & & & & & & & & & & & \\
\hline Schistura novemradiata & & + & & & & & & & & & & & & & & & & & & & & & & & & & & & & & & \\
\hline Schistura nudidorsum & & & & + & & & & & & & & & & & & & & & & & & & & & & & & & & & & \\
\hline Schistura obeini & + & & & & & & & & & & & & + & + & & & & & & & & & & & & & & & & & & \\
\hline Schistura personata & & & & & & & & & & + & & & & & & & & & & & & & & & & & & & & & & \\
\hline Schistura pertica & & & & & + & & & & & & & & & & & + & & & & & & & & & & & & & & & & \\
\hline Schistura pervagata & + & & & & & & & & & & & & & & & & & & & & & & & & & & & & & & & \\
\hline Schistura poculi & + & & & & + & & & + & & & & & & & & & + & & & & & & + & & & & + & & + & & & \\
\hline Schistura porthos & + & + & & & + & & & + & & & & & & & & & & & & & & & & + & & & & & & & & \\
\hline
\end{tabular}


李雪晴, 孙赫英, 何德奎, 陈毅峰, 澜沧江一㯰公河中上游淡水鱼类多样性. 生物多样性, 2019, 27(10): 1090-1100. ttp://www.biodiversity-science.net/CN/10.17520/biods.2019195

\begin{tabular}{|c|c|c|c|c|c|c|c|c|c|c|c|c|c|c|c|c|c|c|c|c|c|c|c|c|c|c|c|c|c|c|c|c|}
\hline \multirow{2}{*}{ 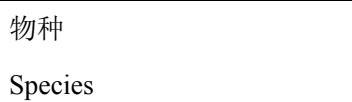 } & \multicolumn{32}{|c|}{ 亚流域代码 Sub-basin codes } \\
\hline & MK-1 & MK-2 & MK-3 & MK-4 & No & NC & CHI & NK & MUN & NN & NNP & SBF & SBH & SK & SG & LS & BJ & HH & sQ & $\mathrm{zQ}$ & AD & YC & $\mathrm{NL}$ & BY & wY & MG & LZ & DZ & $\mathrm{xH}$ & HR & TD & EH \\
\hline Schistura procera & & & & & + & & & & & & & & & & & & & & & & & & & & & & & & & & & \\
\hline Schistura punctifasciata & & & & & & & & & & & & + & & & & & & & & & & & & & & & & & & & & \\
\hline Schistura quaesita & & & & & & & & & & + & & & & & & & & & & & & & & & & & & & & & & \\
\hline Schistura quasimodo & & & & & & & & & & + & & & & & & & & & & & & & & & & & & & & & & \\
\hline Schistura reidi & & & & & & & + & & + & & & & & & & & & & & & & & & & & & & & & & & \\
\hline Schistura rikiki & & & & & & & & & & & & & & + & & & & & & & & & & & & & & & & & & \\
\hline Schistura russa & & + & & & & & & & & & & & & & & & & & & & & & & & & & & & & & & \\
\hline Schistura schultzi & & & & & & & & & & & & & & & & + & & & & & & & + & + & & & & & & & & \\
\hline Schistura sertata & & & + & & & & & & & & & & & & & & & & & & & & & & & & & & & & & \\
\hline Schistura sexcauda & & & + & & & & & & & & & & & & & & & & & & & & & & & & & & & & & \\
\hline Schistura sexnubes & & & & & & & & & & & & & & & & & & & & & & & & & & & & & + & & & \\
\hline Schistura sigillata & & & & & & & & & & + & & & & & & & & & & & & & & & & & & & & & & \\
\hline Schistura sombooni & & & & & & + & & & & & & & & & & & & & & & & & & & & & & & & & & \\
\hline Schistura spiloptera & + & & + & + & & & & & & & & & & & & & & & & & & & & & & & & & & & & \\
\hline Schistura spilota & + & & & & & & & & & & & & & & & & & & & & & & & & & & & & & & & \\
\hline Schistura stala & & & & & & & & & & & & & & & & & + & & & & & & & & & & & & & & & \\
\hline Schistura suber & & & & & & & & & & + & + & & & & & & & & & & & & & & & & & & & & & \\
\hline Schistura systomos & & & & + & & & & & & & & & & & & & & & & & & & & & & & & & & & & \\
\hline Schistura tenura & & & & & & & & & & & + & & & & & & & & & & & & & & & & & & & & & \\
\hline Schistura titan & & & & & & & & & & & & & & + & & & & & & & & & & & & & & & & & & \\
\hline Schistura tizardi & & & & & & & & & & & & & & + & & & & & & & & & & & & & & & & & & \\
\hline Schistura tubulinaris & & & & & & + & & & & & & & & & & & & & & & & & & & & & & & & & & \\
\hline Schistura vinciguerrae & & & & & & & & & & & & & & & & & & & & & & & + & & & & & & & & & \\
\hline Schistura waltoni & + & & & & & & & & & & & & & & & + & & & & & & & & & & & & & & & & \\
\hline Schistura xhatensis & & & & & & & & + & & & & & & & & & & & & & & & & & & & & & & & & \\
\hline Schizopyge dolichonema & & & & & & & & & & & & & & & & & + & & + & & & + & & & & & + & & & & + & \\
\hline Schizopygopsis anteroventris & & & & & & & & & & & & & & & & & & & + & + & & & & & & & & & & & + & \\
\hline Schizothorax griseus & & & & & & & & & & & & & & & & & + & + & + & & + & + & & & & & + & & & & + & + \\
\hline Schizothorax lantsangensis & & & & & & & & & & & & & & & & & + & & + & + & + & + & & & & & & & & & + & \\
\hline Schizothorax lissolabiata & & & & & & & & & & & & & & & & & + & + & + & + & + & + & & & & & + & & + & & + & + \\
\hline Schizothorax nudiventris & & & & & & & & & & & & & & & & & + & + & + & & + & + & & & & & + & & & & + & + \\
\hline Schizothorax taliensis & & & & & & & & & & & & & & & & & & & & & & & & & & & & & & & & + \\
\hline Schizothorax yunnanensis & & & & & & & & & & & & & & & & & + & + & & & & & & & & & & & & & & + \\
\hline Scomberomorus sinensis & & & & + & & & & & & & & & & & & & & & & & & & & & & & & & & & & \\
\hline Sectoria heterognathos & & & & & & & & & & & & & & & & + & & & & & & & + & + & & & & & & & & \\
\hline Serpenticobitis cingulata & + & & + & & & & & & & & & & & & & & & & & & & & & & & & & & & & & \\
\hline Serpenticobitis octozona & & & & + & & & & & & & & & & + & & & & & & & & & & & & & & & & & & \\
\hline Serpenticobitis zonata & & & & + & & & & & & & & & & & & & & & & & & & & & & & & & & & & \\
\hline Setipinna melanochir & & & & + & & & & & + & & & & & & & & & & & & & & & & & & & & & & & \\
\hline Sewellia diardi & & & & + & & & & & & & & & & + & & & & & & & & & & & & & & & & & & \\
\hline
\end{tabular}


李雪晴, 孙赫英, 何德奎, 陈毅峰, 澜沧江一㯰公河中上游淡水鱼类多样性. 生物多样性, 2019, 27(10): 1090-1100. tt://www.biodiversity-science.net/CN/10.17520/biods.2019195

\begin{tabular}{|c|c|c|c|c|c|c|c|c|c|c|c|c|c|c|c|c|c|c|c|c|c|c|c|c|c|c|c|c|c|c|c|c|}
\hline \multirow{2}{*}{$\begin{array}{l}\text { 物种 } \\
\text { Species }\end{array}$} & \multicolumn{32}{|c|}{ 亚流域代码 Sub-basin codes } \\
\hline & MK-1 & MK-2 & MK-3 & MK-4 & No & $\mathrm{NC}$ & CHI & NK & MUN & NN & NNP & SBF & SBH & SK & SG & LS & BJ & HH & sQ & $\mathrm{zQ}$ & AD & YC & $\mathrm{NL}$ & BY & WY & MG & LZ & DZ & $\mathrm{xH}$ & HR & TD & EH \\
\hline Sewellia elongata & & & & + & & & & & & & & & & + & & & & & & & & & & & & & & & & & & \\
\hline Sewellia speciosa & & & + & + & & & & & & & & & & + & & & & & & & & & & & & & & & & & & \\
\hline Sikukia flavicaudata & & & & + & & & & & & & & & & & & + & & & & & & & & + & & & + & & + & + & & \\
\hline Sikukia gudgeri & & & + & + & + & + & & + & + & + & + & + & + & & & + & & & & & & & & + & & & & & & & & \\
\hline Sikukia longibarbata & & & & & & & & & & & & & & & & & & & & & & & & + & & & & & & + & & \\
\hline Sikukia stejnegeri & & & & + & & & & & + & & & & & & & & & & & & & & & + & & & & & & & & \\
\hline Silurus asotus & & & & & & & & & & & & & & & & & & & & & & & & & & & + & & & & & \\
\hline Sinibotia longiventralis & & & & & & & & & & & & & & & & & + & & + & & & + & & & & & & & & & + & \\
\hline Sinibotia superciliaris & & & & & & & & & & & & & & & & & & & & & & + & & & & & & & & & & \\
\hline Speolabeo тизаеi & & & & & & & & & & & & + & & & & & & & & & & & & & & & & & & & & \\
\hline Spinibarbus caldwelli & & + & & & & & & & & & & & & & & & & & & & & & & & & & & & & & & \\
\hline Sundasalanx mekongensis & & & & + & & & + & & + & & & & + & & + & & & & & & & & & & & & & & & & & \\
\hline Sundasalanx microps & & & & & & & & & & & & + & & & & & & & & & & & & & & & & & & & & \\
\hline Sundasalanx praecox & & & & & & & & & + & & & + & & & & & & & & & & & & & & & & & & & & \\
\hline Syncrossus beauforti & + & & & + & & & + & & & + & & & + & + & & + & + & & & & & & + & + & & & & & & & & \\
\hline Syncrossus helodes & + & & + & + & & & + & & + & & & & + & & + & & & & & & & & & & & & & & & & & \\
\hline Syncrossus hymenophysa & & & + & & & & + & & + & + & & & & & & & & & & & & & & & & & & & & & & \\
\hline Systomus orphoides & + & & & + & & & + & & + & + & + & + & & & + & & & & & & & & & & & & & & & & & \\
\hline Systomus rubripinnis & + & & & + & & & + & & + & & + & & + & & & & & & & & & & & & & & & & & & & \\
\hline Systomus sarana & & & & & & + & & & & & & & & & & & & & & & & & & & & & & & & & & \\
\hline Tachysurus fulvidraco & & & & & & & & & + & & & & & & & & & & & & & & & & & & & & & & & \\
\hline Tenualosa thibaudeaui & & & & + & & & + & & + & & & + & & & + & & & & & & & & & & & & & & & & & \\
\hline Terateleotris aspro & & & & + & & & & & & & & & & & & & & & & & & & & & & & & & & & & \\
\hline Thynnichthys thynnoides & + & & + & + & & & + & & + & + & + & & + & & & & & & & & & & & & & & & & & & & \\
\hline Tor ater & & & & & & + & & & & & & & & & & & & & & & & & & & & & & & & & & \\
\hline Tor douronensis & & & & & & & & & & & & & & & & + & & & & & & & + & + & & & & & + & + & & \\
\hline Tor laterivittatus & & & & & & & & & & & & & & & & + & + & & & & & & + & & & & + & & + & & & \\
\hline Tor polylepis & & & & & & & & & & & & & & & & + & & & & & & & + & + & & & & & & & & \\
\hline Tor sinensis & & & + & + & + & & & & & & & & & & & + & & + & & & & & + & + & & & + & + & + & & & \\
\hline Tor tambra & & + & + & & + & & & + & & + & & & & + & & + & + & & & & & & & + & & & & & & + & & \\
\hline Tor tambroides & & + & & & + & + & & + & & & & & & & & & & & & & & & & + & & & & & & & & \\
\hline Toxotes chatareus & & & & + & & & & & + & & & + & + & & & & & & & & & & & & & & & & & & & \\
\hline Toxotes microlepis & & & & & & & & & + & & & & & & & & & & & & & & & & & & & & & & & \\
\hline Trichopodus microlepis & + & & & + & & & & & + & & & & & & & & & & & & & & & & & & & & & & & \\
\hline Trichopodus pectoralis & + & & + & + & & & + & & + & & & & & & & & & & & & & & & & & & & & & & & \\
\hline Trichopodus trichopterus & + & & + & + & + & + & + & & + & + & + & + & + & + & & + & & & & & & & + & + & & & & & & & & \\
\hline Trichopsis pumila & + & & & + & & + & + & & + & & & & & & + & & & & & & & & & & & & & & & & & \\
\hline Trichopsis schalleri & + & & + & + & & + & + & & + & + & & & + & + & + & & & & & & & & & & & & & & & & & \\
\hline Trichopsis vittata & + & & + & + & & + & + & & + & + & + & & + & & + & & & & & & & & & & & & & & & & & \\
\hline Trigonostigma espei & + & + & + & + & & & & & & & & & & & & & & & & & & & & & & & & & & & & \\
\hline
\end{tabular}


李雪晴, 孙赫英, 何德奎, 陈毅峰, 澜沧江一㯰公河中上游淡水鱼类多样性. 生物多样性, 2019, 27(10): 1090-1100. tt://www.biodiversity-science.net/CN/10.17520/biods.2019195

\begin{tabular}{|c|c|c|c|c|c|c|c|c|c|c|c|c|c|c|c|c|c|c|c|c|c|c|c|c|c|c|c|c|c|c|c|c|}
\hline \multirow{2}{*}{$\begin{array}{l}\text { 物种 } \\
\text { Species }\end{array}$} & \multicolumn{32}{|c|}{ 亚流域代码 Sub-basin codes } \\
\hline & MK-1 & MK-2 & MK-3 & MK-4 & No & $\mathrm{NC}$ & CHI & NK & MUN & NN & NNP & SBF & SBH & SK & SG & LS & BJ & HH & sQ & $\mathbf{z Q}$ & AD & YC & $\mathrm{NL}$ & BY & WY & MG & LZ & DZ & $\mathrm{XH}$ & HR & TD & EH \\
\hline Triplophysa brevicauda & & & & & & & & & & & & & & & & & & & + & + & + & + & & & & & & & & & + & \\
\hline Triplophysa dorsalis & & & & & & & & & & & & & & & & & & & + & + & & & & & & & & & & & + & \\
\hline Triplophysa jianchuanensis & & & & & & & & & & & & & & & & & & + & & & & & & & & & & & & & & \\
\hline Triplophysa leptosoma & & & & & & & & & & & & & & & & & & & + & & & & & & & & & & & & + & \\
\hline Triplophysa microps & & & & & & & & & & & & & & & & & & & + & + & & & & & & & & & & & + & \\
\hline Triplophysa orientalis & & & & & & & & & & & & & & & & & & & & + & & & & & & & & & & & & \\
\hline Triplophysa stenura & & & & & & & & & & & & & & & & & + & + & + & + & & & & & & & & & & & + & \\
\hline Triplophysa stolickai & & & & & & & & & & & & & & & & & & & + & + & & & & & & & & & & & + & \\
\hline Troglocyclocheilus khammouanensis & & & & + & & & & & & & & & & & & & & & & & & & & & & & & & & & & \\
\hline Urogymnus polylepis & + & & & + & & & & & + & & & & & & & & & & & & & & & & & & & & & & & \\
\hline Vanmanenia orcicampus & & & & & & & & & & + & & & & & & & & & & & & & & & & & & & & & & \\
\hline Vanmanenia serrilineata & + & + & & & + & & & + & & & & & & & & & & & & & & & + & & & & & & & & & \\
\hline Vanmanenia striata & & & & & & & & & & & & & & & & & + & + & & & & & + & & + & & + & & + & & & \\
\hline Vanmanenia tetraloba & & & & & & & & & & & & & & & & + & + & + & & & & & + & + & & & + & & & & & + \\
\hline Wallago attu & + & & & + & & & + & & + & + & & & + & & & + & & & & & & & + & + & & & & & & & & \\
\hline Wallago leerii & & & + & + & & & & & + & & & & & & & & & & & & & & & & & & & & & & & \\
\hline Xenentodon cancila & + & & + & + & + & + & + & + & + & + & + & & + & + & + & & & & & & & & & & & & & & & & & \\
\hline Xenentodon canciloides & + & + & & + & + & & + & + & + & + & & + & & & & & & & & & & & & & & & & & & & & \\
\hline Yasuhikotakia caudipunctata & & & + & + & & & & & + & & & & & & & & & & & & & & & & & & & & & & & \\
\hline Yasuhikotakia eos & & & + & + & & & + & & + & + & & & + & + & + & & & & & & & & & & & & & & & & & \\
\hline Yasuhikotakia lecontei & & & + & + & & & + & & + & + & & + & + & & & & & & & & & & & & & & & & & & & \\
\hline Yasuhikotakia longidorsalis & & & & + & & & & & & + & + & & & & & & & & & & & & & & & & & & & & & \\
\hline Yasuhikotakia modesta & + & & + & + & & & + & & + & + & & + & + & & & & & & & & & & & & & & & & & & & \\
\hline Yasuhikotakia morleti & & & & & & & + & & + & & & & + & & + & & & & & & & & & & & & & & & & & \\
\hline Yasuhikotakia splendida & & & & + & & & & & & & & & & + & & & & & & & & & & & & & & & & & & \\
\hline Yunnanilus pleurotaenia & & & & & & & & & & & & & & & & & & & & & & & & & & & & & & & & + \\
\hline Zacco platypus & & & & & & & & & & & & & & & & + & & & & & & & & & & & & & & & & \\
\hline
\end{tabular}

